\title{
LAS PLACAS CERÁMICAS DECORADAS TARDOANTIGUAS DE LA SERIE BRACARIO. ALGUNOS APUNTES Y PRECISIONES
}

\author{
THE DECORATIVE TILES OF LATE ANTIQUITY BRACARIO TYPE. \\ SOME NOTES AND CLARIFICATIONS
}

\author{
JOSÉ MANUEL CASTAÑO AGUILAR \\ Arqueólogo. Museo de Ronda. Plaza de Mondragón, s/n. 29400 Ronda. Málaga. \\ Correo-e: jmcastanoaguilar@gmail.com. ORCID: https://orcid.org/0000-0003-2158-4650
}

\begin{abstract}
Resumen: En este trabajo se realiza una revisión de toda la información disponible (histórica, bibliográfica, museística y arqueológica) sobre una serie concreta de placas cerámicas decoradas con iconografía cristiana, para proponer a partir de ella algunas precisiones sobre su origen, cronología y contexto histórico.
\end{abstract}

Palabras clave: Placa decorada, crismón, Antigüedad tardía, Bética, Ronda.

\section{INTRODUCCIÓN}

Sin lugar a dudas, uno de los materiales más característicos de la Antigüedad tardía del sur peninsular son las placas decoradas realizadas a molde que portan decoración en relieve de diferente temática, entre la que destaca la de naturaleza religiosa. Sin embargo, el interés suscitado por la investigación este tipo de elementos ha sido directamente proporcional al desconocimiento arqueológico existente sobre ellas y, hasta cierto punto, al halo de incertidumbre que este hecho ha generado sobre su origen, cronología y función, y que tradicionalmente ha rodeado a estas placas.

Esta ausencia de contextos claros, y quizá también una mala praxis a la hora de interpretar y reinterpretar algunas alusiones antiguas sobre estos objetos, han

\begin{abstract}
In this paper, a review of all the available information (historic, bibliographic, museum-based and archaeological) is developed. We present an analysis on a particular type of decorative tile with Christian iconography, in order to propose some details about its origin, chronology and historical context.
\end{abstract}

Keywords: Tile, Christogram, Late Antiquity, Baetica, Ronda

ocasionado una serie de imprecisiones que, en cualquier caso, no han ayudado a esclarecer las dudas que desgraciadamente la arqueología, precisamente por falta de hallazgos contextualizados, tampoco ha podido aún despejar. Pero dejando su propio curso a la arqueología y a la aportación que algún día podrá hacer esta disciplina sobre el asunto (única fuente de la que cabe esperar algún avance, que de hecho se está produciendo, aunque no con la profusión y rapidez deseables), contamos por el momento con un buen cuerpo de datos que, bien organizados y examinados, pueden ser suficientes al menos para exponer el tema de forma más clara e integrada.

En este trabajo nos vamos a centrar en una de las series más representativas del grupo de placas que llevan iconografía cristiana, en concreto la del crismón, que 
además se completa con una inscripción latina en la que se menciona el nombre de una persona, Bracario. Y nos centramos en esta serie esencialmente por dos razones: la primera por tocar de manera directa nuestra zona de estudio, la Serranía de Ronda, concretamente el área de la depresión o meseta de Ronda; y la segunda razón por ser posiblemente la serie de estos objetos sobre la que existe una información más variada, de diferente origen, que tras ser combinada creemos que puede ayudar bastante a clarificar cuando menos determinadas cuestiones relacionadas con ella.

\section{LAS PLACAS DECORADAS EN EL CONTEXTO DE LA CULTURA MATERIAL DE LA ANTIGÜEDAD TARDÍA DEL SUR DE LA PENÍNSULA IBÉRICA}

La Antigüedad tardía reivindica cada vez con mayor fuerza su lugar como un periodo propio, con características y personalidad propias que, en última instancia, se verán reflejadas en una cultura material con rasgos también particulares. Porque, si bien es cierto que se trata de un momento en el que resulta evidente la huella de la Antigüedad esencialmente romana, también es verdad que, por propia decantación, lo que se comprueba es una reelaboración de la tradición clásica que se manifiesta de diferentes maneras en función de las idiosincrasias que demuestran las antiguas provincias del Imperio (Cameron 1998; Wickham 2008; o, con implicaciones negativas, Ward-Perkins, 2007).

La desarticulación progresiva del comercio a larga distancia, sobre el que se sustentó en buena medida Roma, hará que se produzcan interpretaciones de la gran herencia material romana que, conforme vayan pasando los años, se irán haciendo tanto más localistas cuanto mayor fuera la degradación de los sistemas de intercambio y de sus flujos de comercialización. El ejemplo más claro, posiblemente por la gran tradición en los estudios y por contar con mejores contextos, son las cerámicas, que cabalgan, en el momento que nos interesa, entre la desaparición de las sigillatas y la generación de series o tipos particulares, como las jarritas visigodas, o los cuencos evolucionados a partir de las TSHTM (Caballero et al. 2003). Pero no solo en las cerámicas se habrá de notar la evolución cultural que parece darse en lo que convencionalmente se ha determinado como "Hispania visigoda". Exceptuando los ajuares domésticos y la toréutica, los elementos de la cultura material mejor definidos para este momento (entre los siglos VI y VIII d.C.) son, sobre todo, los relacionados con la decoración arquitectónica, entre la que podríamos inscribir las placas cerámicas decoradas a molde.

Que la dispersión de estas piezas se localice esencialmente en la Bética quizá sea una prueba más de esa progresiva regionalización que experimentarán determinados elementos, cuyos paralelos en otras áreas de la Península habría que buscar en objetos similares aunque elaborados en piedra, como los conocidos nichos-placa, canceles u otros elementos ornamentales (Morín de Pablos 2014). Lo cierto es que, desde los ejemplares con decoración geométrica o vegetal fechados hacia el siglo $\mathrm{V}$, hasta los caracterizados por representaciones figuradas de diferente tipo, entre los que se encuentran los que llevan crismón (el anagrama de Cristo), para los que no existe un consenso unificado y claro en cuanto a su cronología, todos ellos (al menos los que cuentan con procedencia conocida) han sido hallados, con o sin un contexto arqueológico definido, en la Bética: villas de Manguarra y San José, en Cártama (Serrano Ramos 1973), Finca de El Secretario, en Fuengirola (Hidalgo Aguilera 2003), Osuna (Loza Azuaga 1992, Román y Ruiz 2007), Antequera (Romero et al. 2013-2014) o diferentes lugares de las provincias de Sevilla y Córdoba (Ruiz Prieto 2012, Castelo Ruano 1996). De hecho, esta circunstancia hizo que se propusiera en un primer momento un origen norteafricano, pasando desde aquí a la Península como ocurriría con otros materiales, como las ARSW, aunque con la diferencia de haberse desarrollado con posterioridad en nuestro territorio o, incluso, de haberse anticipado a algunos de los tipos norteafricanos (Loza Azuaga 1992: 252).

El interés por estas piezas cerámicas viene de antiguo, aunque no se haya reflejado en estudios exhaustivos (hasta fechas relativamente recientes). En la historiografía hispana las primeras referencias a ellas en trabajos de cierta relevancia no son anteriores al siglo XIX, lo que no impide que puedan encontrarse menciones en escritos anteriores, como se verá. Por lo general, se trata de citas puntuales que en la mayor parte de las casos se limitan a levantar acta o dejar constancia del hallazgo de algún o algunos ejemplares en tal o cual sitio, y a lo sumo ofrecer detalles llamativos de los descubrimientos o de las piezas: hallazgos de placas de la serie "FELIX ASELLA" en Puente Genil (Oliver y Hurtado 1866: 43, Aguilar y Cano 1894: 740 ); en esta misma localidad, hallazgo de ejemplares de la serie "IMERIVS", en realidad "SALVO IMERIO" en combinación con la leyenda anterior - "Salvo 
Imerio/Felix Asella"- $\left(C I L \mathrm{II}^{2} / 5,905=C I L\right.$ II 4967,36 $=E E$ VIII $259=I L C V 52=I H C 197=I H C 432=$ ICERV 411), tal y como puede verse en el Museo de Puente Genil (Esojo Aguilar 2013), a los que habría que sumar algún ejemplar de "ISIDORVS" encontrado al parecer en Lucena (Sánchez et al. 2009). Con una fórmula parecida pero dedicada esta vez a un tal "Ausentio" ("salvo Ausentio") e inscrita en los cantos (CIL $\mathrm{II}^{2} / 5,469 \mathrm{a}=$ CIL II, 6253,03,01 = CILA II/1, $160=$ $I H C 436 \mathrm{a}=I C E R V$ 408), son las placas halladas en Espejo, Córdoba (Marcos Pous 1981); igualmente en los cantos, piezas con la inscripción "CHIONI VIVAS" $\left(C I L \mathrm{II}^{2} / 5,980=C I L\right.$ II, 4967,35 = ILCE $857=I H C$ $196=C I L A$ II, $673=C I L A$ II, 1252) procedentes al parecer de una tumba de Martos (Recio y Fernández-Chicarro 1959: 153), y que se hallaron también en Osuna (Oliver y Hurtado 1866: 58); otros ejemplares aparecidos en Montilla (Romero de Torres 1911), o en otros lugares de la provincia de Córdoba (Romero de Torres 1919), o los hallados en esta misma ciudad hacia mediados de los años 1950 con la inscripción MARCIANE VIVAS IN + (crismón) $\left(C I L \mathrm{II}^{2} / 7,195 \mathrm{a}=C I L\right.$ II, 4967,40 = IHC 203,1 a = ICERV $414=I C E R V 584$ $=I L C V 2221=$ SEBarc 10 (p. 244)), y que poseen la particularidad de mostrar la decoración sobre una tabla horizontal de las placas - la mayoría se realiza sobre una tabla vertical- (González y Moreno 1997). Completarían este rápido repaso los ejemplares hallados en Ronda y Morón de la Frontera pertenecientes a las series "BRACARIO" (CIL II, 4967,32 = IHC $434=A E$ 1986, $326=$ ILMMalaga $48=$ CILA II, 161) y "MARCIANO" (CILA II/4, $1217=$ IHC $437=I L C V 915=$ ICERV $409=$ HEp 1997, 876 = AE 1986, 327), respectivamente (Fita 1908). Terminamos con el que sería el único caso conocido de uno de estos ejemplares encontrado en Extremadura, que además pertenece a nuestra serie: se trata de un fragmento de placa de "Bracario" conservado en el Museo de Cáceres, donado por Juan Milán en 1951 y cuya procedencia se desconoce. En aquel entonces ya era el único conocido, una excepción que continúa 70 años después (Callejo Serrano 1962: 247). A estas habría que sumar las de procedencia dispar, aunque mayoritariamente desconocida, contenidas en colecciones y museos, y que comenzaron a formar parte de inventarios y catálogos. Entre los más tempranos tenemos los casos del Museo Arqueológico Nacional (Rada Delgado 1876), o de la colección Loringiana, que posteriormente pasó a formar parte de los fondos del Museo de Málaga (Rodríguez Berlanga 1903), de cuyo catálogo existe una actualización (Serrano y Atencia 1981); o el trabajo ya citado de
Recio y Fernández-Chicarro (1959), sobre una colección particular de Martos.

A partir de ahí son algunos los trabajos que han abordado el estudio de colecciones de placas decoradas en fechas ya más cercanas a nosotros. Quizá el más conocido, probablemente por inaugurar la nueva etapa en el estudio de estos elementos ornamentales, haya sido el que Raquel Castelo desarrolló sobre las conservadas en la Fundación Alhonoz de Écija (Castelo Ruano 1996). Pero antes de él ya existía algún trabajo centrado de forma monográfica en alguna serie específica de placas con inscripción conservadas en museos. Tal es el caso del estudio de A. Marcos sobre los ladrillos con la fórmula "SALVO AVSENTIO" inscrita en sus cantos, depositados en el Museo de Córdoba (Marcos Pous 1981); el de Carmen Martín sobre los ejemplares decorados del Museo de Sevilla (Martín Gómez 1982), trabajo mejorado y ampliado recientemente por E. Ruiz (Ruiz Prieto 2012); o la relectura realizada por M ${ }^{\mathrm{a}}$ Luisa Loza de los del Museo de Málaga, que en sí misma supuso una referencia para posteriores estudios (Loza Azuaga 1992). Y en un ámbito más local, citamos los estudios de las colecciones de placas conservadas en Osuna (Román y Ruiz 2007) o la misma Ronda (Ruiz Torres 2006).

Con la profusión de intervenciones arqueológicas desarrolladas en los años previos a la crisis, han aumentado los ejemplares hallados en contextos arqueológicos. Sin embargo este aumento no ha sido exponencial, si se tiene en cuenta el número de intervenciones realizadas, y todavía resulta menos relevante si las consideramos según su serie. Así, por ejemplo, la mayoría de los hallazgos de placas pertenecen a series en las que se representan motivos geométricos o vegetales: desde los antológicos primeros hallazgos de los años 1970-1980 en varias villas de la provincia de Málaga (Serrano Ramos 1973, Puertas Tricas 1986-1987, Hidalgo Aguilera 2003), a los más recientes producidos esencialmente en la vega de Antequera y algunos puntos del valle del Guadalquivir; como en la provincia de Córdoba (Vargas et al. 2007a, Castro et al. 2006, Vargas et al. 2007b, Lara et al. 2002), o en la ciudad de Sevilla (Ruiz y Román 2015: 15); aunque bien es cierto que no faltan los casos en los que se puede encontrar algún nombre de persona. De estos últimos y en el ámbito de la arqueología preventiva, tal vez el hallazgo más relevante sean los 31 ejemplares decorados con simbología cristiana, entre los que se encontraba uno completa con la inscripción "ISIDORE VIVAS / OPTATA VIVAS", descubiertos en la villa de Caserío Silverio Mayorga de Antequera, 
Málaga (Romero et al. 2013-2014: 263), y conocidos con antelación por un ejemplar de Utrera (González Fernández 1988). Más modesto es el fragmento de la serie Marciano encontrado en el Patio de Banderas del Alcázar de Sevilla (Tabales Rodríguez 2015: 215), si lo comparamos con los numerosos ejemplares de la misma serie hallados en Morón, tanto en excavación (Vera Reina 1999), como en prospección arqueológica (Vera Reina 2000: 41), contexto este último similar a muchos de los custodiados en el Museo de Ronda (Ruiz Torres 2006).

Sin haber pretendido ser exhaustivos en este breve repaso, las referencias mostradas nos parecen suficientes como reflejo del papel que han representado estos objetos cerámicos entre los estudios centrados en la Antigüedad tardía del sur peninsular, y principalmente en los antiguos territorios de la Bética. Pero como se desprende asimismo de este rápido repaso, resulta evidente la carencia total y absoluta de estudios arqueométricos y tipológicos sobre estas piezas; falta debida, tal vez, a una especie de complacencia o acomodación al nivel de conocimiento que albergábamos sobre ellas y que, en buena parte, puede deberse a la señalada insuficiencia de contextos y secuencias arqueológicas a las que poder adscribir estas placas decoradas. Y aunque sabemos que no están todas las que son, lo cierto es que las intervenciones arqueológicas que han proporcionado contextos para ciertas series de placas no han logrado despejar algunas de las incógnitas que, por tanto, las siguen atenazando, como por ejemplo la determinación más exacta de sus cronologías. Es ciertamente desolador que con el gran avance que se ha experimentado en las últimas décadas en los estudios cerámicos, concretamente en la precisión de cronologías, y a pesar de la existencia de contextos (aunque sean de diferente naturaleza o carácter), todavía encontremos que las referencias más exactas al marco temporal en el que se podrían inscribir estas piezas se sitúen en una horquilla de más de dos siglos (ss. V al VIII, en algunos casos). Solo cuando aparecen nombres propios en algunas de ellas, y se pueden atribuir a personajes cronológicamente conocidos, se aventuran propuestas de datación relativa, aunque existan casos en los que, ante una dualidad nominal, se prefiera siempre optar por el nombre de mayor antigüedad, sin que se justifique suficientemente tal decisión (Ruiz y Román 2015: 41).

En la actualidad, y con los datos proporcionados hasta el momento, encontramos que se podrían establecer con cierta claridad dos bloques de placas a los que atribuir, al menos, cronologías relativas basadas en sus contextos cerámicos mejor definidos. Por un lado tendríamos los ejemplares decorados con motivos geométricos y vegetales, hallados generalmente en villae tardoantiguas con contextos relativamente bien definidos en el siglo $\mathrm{V}$, como son los casos ya comentados de las villas malagueñas de la costa. Por otro lado estarían los decorados con simbólica cristiana, no importa de qué tipo, pero entre los que tienen una especial incidencia aquellos que llevan el anagrama de Cristo. Mirando sus contextos, escasos pero existentes, y las posibles coincidencias entre personajes de cierta relevancia y determinados nombres propios en algunos de ellos, en ningún caso parecen anteriores al siglo VI o, a lo sumo, a finales del anterior, siendo la mayoría propuestos en la centuria siguiente, esto es, en el siglo VII. Pero como nuestro objetivo no es este y además se ciñe a una serie concreta, pasaremos a otro apartado.

\section{SIMBOLOGÍA, SIGNIFICADO Y FUNCIÓN DE LAS PLACAS CERÁMICAS DECORADAS.}

Una de las cuestiones que más han llamado la atención de los investigadores sobre estas placas cerámicas es la relacionada con la intencionalidad y función con la que se fabricaron y, por supuesto, con el significado de los símbolos representados en ellas. En esta ocasión nos centraremos con exclusividad en las que poseen simbología cristiana porque atañen directamente a la serie que estudiamos en este trabajo.

Diferentes símbolos permiten apreciar el carácter religioso cristiano de estas placas y de otros soportes ornamentales como las cerámicas: palomas, pavos, palmas, peces, por supuesto cruces, e incluso menoráh, el candelabro judío de siete brazos por cuyo empleo en comunidades cristianas aboga alguna investigación (Barroso y Morín 1994: 284; en contra, Stylow 2005: 218). Sin embargo, se debe coincidir en que el símbolo de estas características más extendido y reproducido es el crismón, también llamado anagrama de Cristo o cristograma. Y tal vez sea el más extendido por su origen imperial, ya que fue este anagrama el que empleó el emperador Constantino como representación en el lábaro o estandarte.

El hecho de que algunas de estas placas hayan sido descubiertas al parecer en contextos funerarios, según las noticias de estos hallazgos (Benaoján, Martos, Osuna), pues ninguna de las documentadas con metodología arqueológica se puede asociar a una tumba, ha sido una de las causas por la que, en su momento, 
se consideró posible que hubieran servido de revestimiento de tumbas (De los Santos Jener 1958: 181, De la Rada Delgado 1876). Tal vez la presencia de hortationes de carácter religioso, consistentes en una intitulatio seguida de una construcción del tipo VIVAS CVM TVIS, VIVAS IN CHRISTO o similar (Santiago Fernández 2009: 237), haya servido para reforzar esta función, interpretando que el individuo referido (o uno de ellos en los casos en los que se registran dos) es, en este caso, el ocupante de la sepultura, o sencillamente al que están dedicados estos objetos, eso sí, tras haber fallecido (Castillo Maldonado 2005: 346). Sin embargo, y a pesar de las dudas que pueden aún existir, sí que contamos con algunas referencias directas e indirectas que apuntan hacia la que parece ser la dirección más correcta en relación a su función: la de haber servido como revestimiento de forjados planos, formando casetones. Hallazgos como el de la Casa del Sectile en Sevilla, o el más llamativo de Caserío Silverio de Antequera son dos evidencias que parecen apoyar esta lectura, a la que se suman la mayoría de investigadores que han tratado el tema, y que se ve respaldada además por una característica presente en todas estas piezas, como son las partes sin decorar y su diferenciación con las que sí lo están mediante resaltes o rebabas de diferente tipo (Ruiz González 2014: 115). En este caso podría ser válida una explicación similar en cuanto a su finalidad, solo que al tratarse de edificios principalmente de carácter religioso y por tanto para el culto, no necesariamente la persona referida y la que hace uso del templo tienen que ser la misma, por lo que cabe aquí la posibilidad de que sea el benefactor o, en casos de dignidades eclesiásticas como los obispos, el consagrante (Santiago Fernández 2009: 238).

Así pues, por la misma razón la investigación actual trabaja cada vez más con la probabilidad de que sus espacios de procedencia (al menos el de los ejemplares con crismón) sean iglesias o lugares de culto pues, aparte de los casos en los que se propone directamente esta opción, como en Morón (Vera Reina 1999) o en Osuna (Ordóñez y Ruiz 2015a). En este último municipio, en el emplazamiento en donde se han encontrado algunas de estas placas decoradas, se conservan además algunos topónimos que inciden en dicha función. Así por ejemplo, el yacimiento que se llama "la Piedra o Peña del Cristiano" está situado en un paraje conocido como "Guadalelaire" (topónimo hoy vinculado a un cortijo), que quizá pueda relacionarse a algún "wadi al-dayr", o río del monasterio, cuyo topónimo ha llegado hasta nosotros en la versión arabizada del término. Parece más que una mera coincidencia la relación de estos topónimos y el hallazgo de placas cerámicas con simbología cristiana.

Así mismo, también se baraja la conversión de antiguas estancias de villae bajoimperiales en espacios dedicados al culto, que se cerrarían con techos decorados por estos elementos cerámicos. Un ejemplo de tal reutilización sería el de la villa de Caserío Silverio (Antequera, Málaga), cuyo peristilo parece que se convirtió en una especie de capilla, a tenor de la cantidad de piezas de estas características halladas en sus últimos niveles de uso (Romero et al. 2013-2014).

\section{LAS PLACAS DECORADAS DE LA SERIE BRACARIO. REFERENCIAS.}

Las placas cerámicas decoradas con crismón que llevan la leyenda "Bracari vivas cum tuis” (¡Bracario, que vivas -en Cristo- con los tuyos!) posiblemente son, junto con las de las series Marciano, Asella o Himerio (otras intitulaciones), las más características del abanico de series que se documenta en la Bética durante la Antigüedad tardía. En cualquier caso, de lo que no cabe duda es de que se trata de una de las más conocidas y citadas por la bibliografía, casi con seguridad la que mayor número de ejemplares ha dado y, consecuentemente, la que mayor dispersión presenta en instituciones museísticas del país y de fuera de él. Al mismo tiempo es quizá el referente de placas con crismón del que se tienen noticias más antiguas, así como el que cuenta con algún contexto arqueológico que permita integrarlas en una determinada dinámica histórica, aunque este contexto provenga de la arqueología extensiva o territorial, es decir, de registros arqueológicos de superficie.

Son entonces los ejemplares de la serie Bracario los que cuentan con suficientes referencias históricas, bibliográficas, museísticas y arqueológicas como para que, sobre ellos, se sigan manteniendo algunas cuestiones para las que ni siquiera se tenía la más mínima base en el momento en el que fueron planteadas. Las más llamativas son las relacionadas con su origen, dispersión y posible identificación del personaje, entre las que pueden encontrarse propuestas que difícilmente soportan un sencillo contraste con la información disponible. Por tanto uno de nuestros objetivos ha sido reunir todas las referencias sobre estos objetos que hemos podido recabar, para poder evidenciar esas imprecisiones y sustentar mejor nuestras propuestas al respecto. 


\subsection{Referencias históricas sobre las placas cerámicas decoradas de la serie Bracario}

La historia de estas placas cerámicas no es precisamente rica en detalles. Más bien al contrario. Sin embargo, sobre estas piezas sí que existen algunas noticias que han quedado fijadas en distintos escritos y diversas épocas, y que, a diferencia de las de carácter arqueológico, permiten inferir determinadas conclusiones de gran interés para el objetivo que nos hemos propuesto en este trabajo.

Una de estas fuentes, quizá la principal, es una carta que envía Diego de Maraver, natural de Ronda, en el año 1610 a Bernardo de Aldrete, canónigo de la Catedral de Córdoba y experto en temas arqueológicos. Esa carta, fechada en Ronda el 28 de agosto, contiene la que posiblemente sea la primera mención no ya del tipo que nos ocupa, sino de estas placas decoradas en general. Es por ello, por lo que se constituye sin ningún género de duda en un documento esencial para contextualizar esta serie con crismón, así como para explicar algún que otro error posterior, como el del hallazgo de más de un centenar en Alcalá del Río que cita Gómez-Moreno, pero del que no da más referencias; lo que nos lleva a considerarla una noticia corrompida a partir del descubrimiento de Ronda (Gómez-Moreno 1966: 111). En esa carta, en la que se abordan diferentes temas arqueológicos de la ciudad y de sus alrededores, se dice:

Está cerca de esta ciudad, junto a la huerta de el señor Raphael (...) un edificio antiguo arruinado que sirve oy de un suelo de lagar y bodega a donde se hallaron gran cantidad de ladrillos maravillosos de tiempo de el emperador Constantino con la señal del Labaro en ellos de relieve, que son la $\mathrm{C}$ y la $\mathrm{R}$ griegas que notan el nombre de Christo nuestro Señor. Yo he visto dos de ellos (...) y el uno tiene por orla asi mesmo de relieve, Braccare vivas cum tuis... (Rubio Lapaz 1994: 183).

Por las pistas que da, parece obvio que el lugar al que se refiere es el paraje conocido como "Lagar de Peinado"; cortijo próximo a Ronda (a unos 3 o $4 \mathrm{~km}$ ) en cuyos dominios se han hallado muchas de estas piezas decoradas, incluida la que se conserva completa en el Museo de Ronda. Lagar de Peinado es un yacimiento caracterizado asimismo como una gran villae bajoimperial y tardoantigua, de la que se conocen incluso estructuras visibles hoy en la linde del camino que conduce al cortijo, pero que desafortunadamente no ha sido investigada mediante excavación.

Si la noticia anterior se podría considerar con toda probabilidad la primera ocasión en la que se registra textualmente este tipo de objetos cerámicos, en fechas no muy posteriores, seguramente como consecuencia del impacto originado entre la erudición local por el hallazgo de Lagar de Peinado, se registra el que podría ser igualmente el primer dibujo o ilustración de uno de ellos realizado por otro historiador local hacia la segunda mitad del siglo XVII. En su Antigüedades de Ronda, Macario Fariñas incorpora la ilustración de esta placa acompañada de una escueta mención a la distancia de Ronda a la que suelen aparecer estos ladrillos "maçarís" procedentes, según él, de "entierros de cristianos" (Fariñas del Corral 2014: 261) (fig. 1). No dice nada más sobre ellos, tal vez porque su atención se centra en otras cuestiones relacionadas con la Edad Antigua, particularmente de Ronda y de Acinipo, conocida ya por entonces, pero la ilustración no deja margen para dudar de que se trata de ejemplares de la serie Bracario, lo que viene a reforzar esa exclusividad o, al menos, particular relación entre estos y la zona de Ronda.

A partir de aquí, las menciones que encontramos en los textos de los historiadores locales o de los que han tratado de alguna forma cuestiones de carácter histórico y arqueológico de la comarca, no hacen más que repetir el descubrimiento registrado a comienzos del siglo XVII en el área mencionada, también conocida como Llanos de Aguaya. Así lo recoge un recopilador de informaciones históricas como fue Juan María Rivera Valenzuela (Rivera Valenzuela 1873: 52), o Juan José Moreti quien, aparte de este lugar, refiere su aparición en "varios sitios de esta ciudad" (Moreti Sánchez 1867: 151). En el siglo XVIII la misma noticia había rebasado las fronteras de la Serranía de Ronda y de la misma Andalucía, como pone de manifiesto el hecho de que la encontremos en un manuscrito copiado de un original de Francisco A. Forner, médico emeritense de la segunda mitad del siglo XVIII:

En el campo de este pueblo en un lugar llamado los llanos de Aguaya estaba un hombre cabando cabando y el mismo arado saco un Ladrillo y quando se supo fueron muchos curiosos y continuaron en cabar y an sacado mas de ciento de ellos (...) Estos ladrillos estaban preparados para algun sepulcro, el qual no llego a efectuarse mediante a estar amontonados unos sobre otros (...) La inscripción que se haya alrededor dice BRACARI VIVIAS CVM TVIS, Lo que quiere decir Bracario vive con los tuios (esto es con los Catolicos) y junto esto a los demas dice, en Jesuchristo principio y fin de todas las cosas (...) (Cerrillo Martín de Cáceres 2010: 83).

En ella, aparte del lugar (Llanos de Aguaya), y de que podrían pertenecer a un sepulcro que no llegó a 
ejecutarse, de ahí que aparecieran "cientos de ellos... amontonados", se transcribe y traduce la leyenda que enmarca la placa, algo que no encontramos en los anteriores, salvo en la ilustración que de la misma hace Juan José Moreti (Moreti Sánchez 1867: 838).

Pero aunque se trate del hallazgo más llamativo y numeroso, el de Llanos de Aguaya o Peinado no fue el único que dejó rastro en la documentación escrita. En 1772 se encontró una placa del mismo tipo en las Viñas del Concejo de Benaoján, pueblo muy cercano a Ronda. Según el autor que se hace eco del descubrimiento, Cristóbal Medina Conde, historiador de la segunda mitad del siglo XVIII, se trataba de un ejemplar "de dos cuartas de largo y una de ancho", con la inscripción "Bracari vi/vas cum tuis", cuya función y origen relacionaba también con la presencia de una sepultura (Medina Conde 1789: 300): En la villa de Benaoján "se encontró a media legua de ella en 1772 en el sitio que llaman las viñas del Concejo un sepulcro cristiano, como lo indica la inscripción exarada en un ladrillo de dos cuartas de largo y una de ancho, cuya copia es como sigue: Bracari ui/uas cum tuis". Sin embargo, al contrario que en el descubrimiento primigenio, solo se cita una, por lo que habría que suponer que esta última observación debió basarse en la realizada por los autores anteriores, pues tampoco en esta ocasión se documentaron, al parecer, restos humanos que sirvieran de contexto. Aparte de la mención, C. Medina incorporó dos dibujos, uno bastante idealizado, por lo que se trata de la segunda ocasión en la que se ilustra un ejemplar de la serie Bracario, y de nuevo a partir de un ejemplar encontrado en la meseta rondeña (fig. 2).

La primera puntualización o precisión que podríamos realizar, según lo expuesto, indica que las referencias escritas más antiguas sobre estas placas decoradas, y nos atreveríamos a decir que las más antiguas igualmente sobre cualquiera de las demás series de placas halladas en la Bética, proceden de autores de Ronda que registran el que quizá sea también el primer descubrimiento de estos materiales producido, precisamente, en los alrededores de esta ciudad. Ambrosio de Morales, en su libro Las Antigüedades (1575), no cita ni esta ni otras piezas similares, como se asegura en alguna publicación (Román y Ruiz 2007). Al respecto, tan ilustrativas como las referencias que se han citado, pueden llegar a ser algunas ausencias significativas en obras de finales del siglo XIX, época en la que ya eran de sobra conocidas. Un ejemplo llamativo es el de la "Munda pompeyana" de José Oliver y Hurtado (1866). En esta obra no se menciona la presencia de placas decoradas

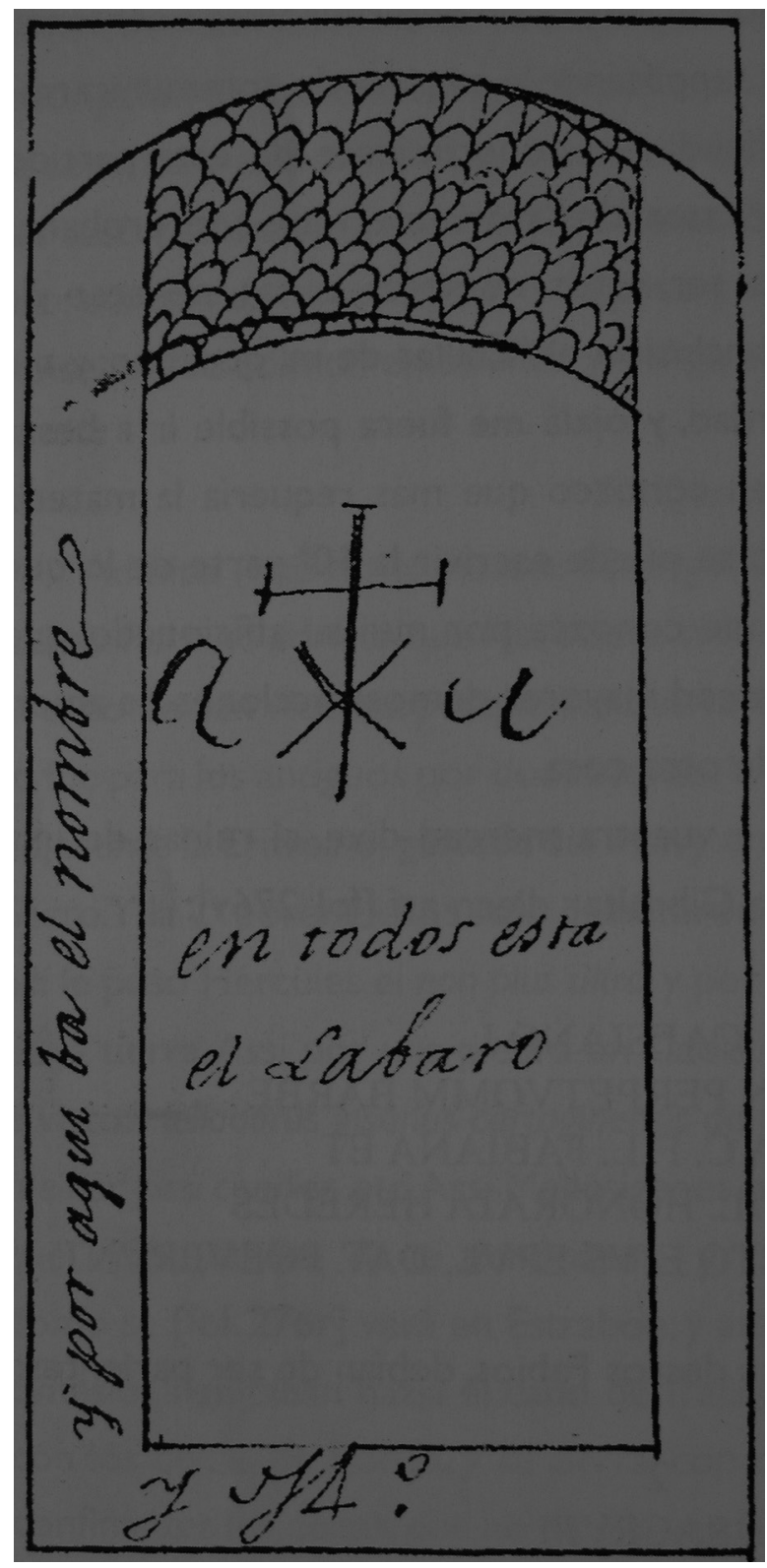

Figura 1. Dibujo realizado por Macario Fariñas del Corral (c 1660: 262).

en el área rondeña (Oliver y Hurtado 1866: 70). El hecho de que sí cite ejemplares de otros lugares en su trabajo (por ejemplo, Puente Genil, pág. 43) y no las rondeñas, puede deberse a que estas últimas en la comarca de Ronda solo aparecen en los alrededores de la propia ciudad, lo que explicaría su ausencia al no estar incluida Arunda en la discusión sobre la localización de la Munda en la que se enfrentaron los ejércitos partidarios de César y del difunto Pompeyo. 

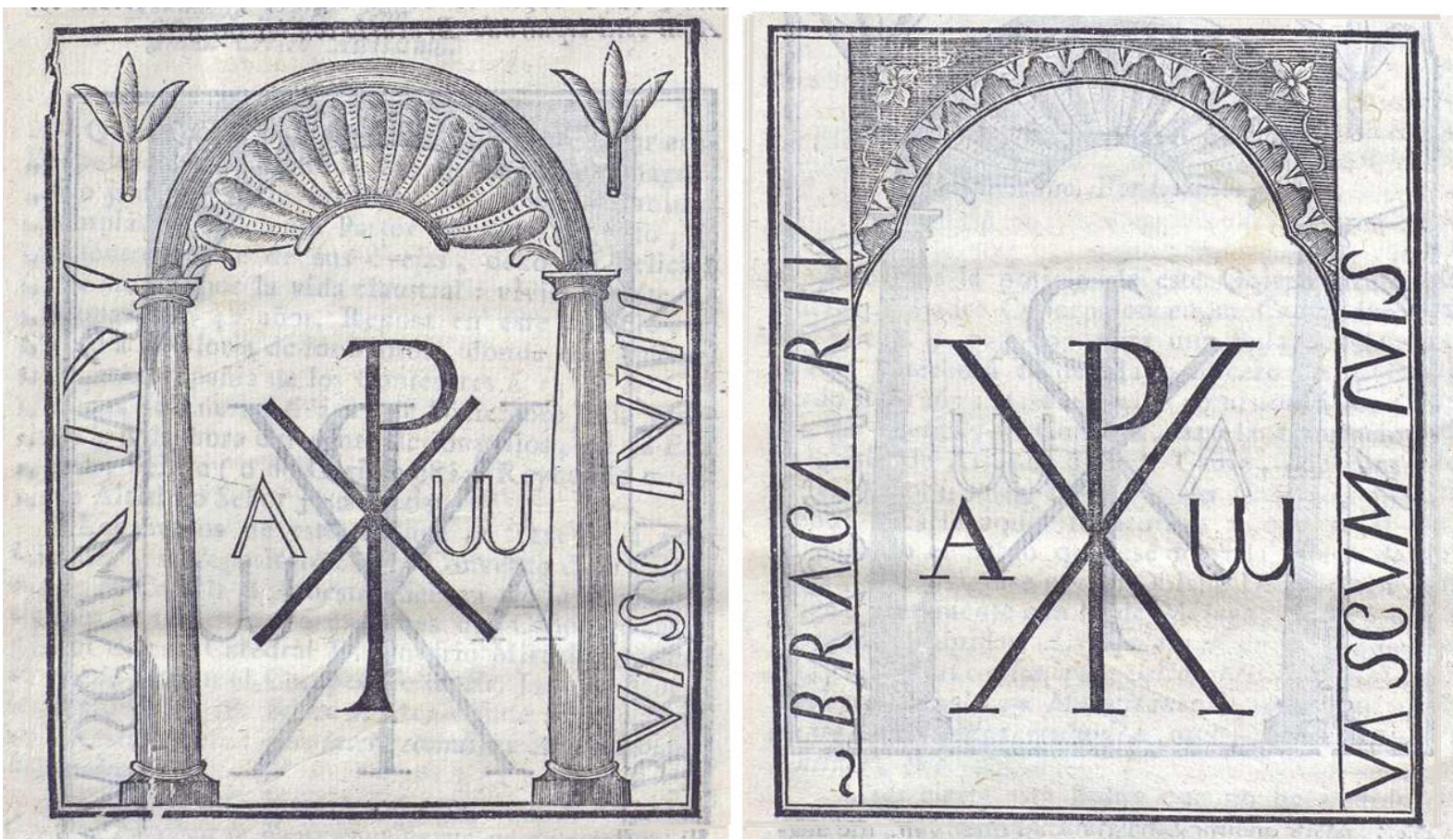

Figura 2. Dibujos de Bracarios realizados por Medina Conde (1789: 301-302).

\subsection{Análisis bibliográfico}

En este apartado vamos a analizar los trabajos que proporcionan algún tipo de información sobre esta serie en concreto, aunque no se trate de estudios centrados en exclusiva sobre la misma. Por regla general suelen incorporar detalles sobre su procedencia, sobre su función, o sobre su posible cronología, además de ofrecer referencias relativas a los aspectos formales de la pieza: esto es, a su composición iconográfica y a su leyenda. Por otra parte, casi todas estas obras analizan ejemplares ya conocidos, bien por la propia bibliografía, o bien porque se encuentran en instituciones o colecciones museísticas. Pero de esos tres rasgos que se podrían utilizar para definir la serie, quizá sea el de la procedencia el más recurrente y el que mayor coincidencia presenta en casi todas las obras, por lo que será sobre ella sobre la que incidamos especialmente en este rápido repaso. Cuestión menor en estos escritos ha sido la discusión sobre su posible cronología, seguramente por la falta de contextos claros, o el de la finalidad o función para las que fueron creados estos materiales. Las consideraciones que se han tenido al respecto en el apartado anterior serán suficientes para contextualizar también nuestra serie. Pero una vez centrados en el tema de su posible procedencia, también aquí se podrían señalar algunas diferencias entre estos trabajos, que básicamente se reparten entre los que fijan el origen de estos ejemplares en la zona de Ronda, y los que no lo hacen, o proponen áreas geográficas extensas.

La primera referencia a placas cerámicas de la serie Bracario que encontramos en la bibliografía especializada se debe a Emil Hübner, quien incorporó este tipo de soportes inscritos (tegulae según él) en su Corpus Inscriptionum Latinarum -CIL II, 4967, 32- (Hübner 1869: 663), y en su Inscriptiones Hispaniae Christianae-IHC, 193-(Hübner 1871: 65) (fig. 3). Pero la verdadera importancia del dato no está en ser la primera referencia escrita sobre la serie, pues en sentido estricto no lo es como se verá, sino en señalar por primera vez los posibles lugares de procedencia, y constituir a partir de ahí el error más recurrente en relación a estas tegulae christianae; un error que se repetirá sin cesar hasta nuestros días. Según Hübner, estas piezas aparecieron en Arunda, Benaoján, Ilipa (Alcalá del Río), Hispalis, Astigi, así como en otros lugares de la Bética que no relaciona. Sin embargo, para describir la serie únicamente recurre al dibujo y descripción que ofrece Medina Conde del ejemplar hallado en Benaoján, lo que induce a pensar que Hübner no vio ninguna de las otros que atribuyó a las demás localidades. 


\section{Tegulae christianae.}

\section{Tegulae repertae Arundae (Gibraltare apud Iosephum Salazar; 'en Benajoan' Conde); llipae (en el silio llamado los Llanos); Hispali (in sepulcreto detecto in horto palatii de Sant Elmo, olim servatae apud Nathanem Wheterell, nune apud ducem de Montpensier); Astigi (apud Marianum Casaubon), aliisque Baeticae locis (in mus. Matrit.). Est anaglyphum in superficie tegulae.}

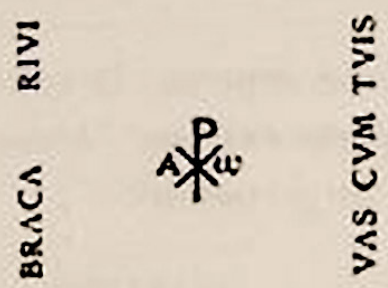

Bracari viras cum this

\section{Descripsi exempla non pauca, alia ab amicis accepi depicta; Conde convers. Malag. 2, 301.}

Figura 3. Detalle de la ilustración que acompaña al tipo descrito por E. Hübner, CIL II, 4967, 32.

Esta fue una práctica muy común en toda su monumental obra, pues de lo contrario hubiera sido imposible abordarla relativamente en tan poco tiempo: la de realizar un vaciado de las noticias que mencionaban inscripciones romanas insertas en obras de diferente naturaleza, fundamentalmente, como es obvio, de carácter histórico. No es de extrañar por tanto que se produjeran algunas imprecisiones, ya que en ocasiones las filiaciones geográficas las realizaba basándose en los pocos datos que encontraba en la literatura erudita disponible en su tiempo. Este parece, a nuestro entender, que fue el caso de la atribución de hallazgos de placas cerámicas de Bracario a las tres últimas localidades: Ilipa, Hispalis y Astigi, pues en ninguna de ellas hemos encontrado mención alguna al descubrimiento de estas piezas, incluida la recientemente publicada Carta Arqueológica Municipal de Alcalá del Río (Fernández et al. 2011: 202).

Resulta, por tanto, bastante extraña la referencia que da Manuel Gómez-Moreno sobre el hallazgo de más de un centenar en esta localidad, y que achacamos posiblemente a una confusión con el acaecido en Ronda (Gómez-Moreno 1966: 111). Lo mismo cabría decir de las dos ciudades restantes, aunque con matices, pues en una de ellas sí que han aparecido algunos ejemplares, aunque de otra serie, como es el caso de Hispalis. Para mayor abundamiento, el que Hübner dice que procede de Hispalis acabará en el Museo Arqueológico Nacional, en donde lo ve Juan de Dios de la Rada quien, como el anterior, dice que perteneció a Nathan Wetherell, aunque añadiendo sobre este señor que era vecino de Sevilla, y sobre la placa, que su procedencia es completamente desconocida incluso para D. Joaquín Guichot quien, por aquel entonces, se hallaba inmerso en la redacción de una Historia de Sevilla (De la Rada Delgado 1876: 593). A pesar de esto, su repetición en trabajos posteriores será recurrente, de lo que se deduce que tampoco en estos casos se ha procurado contrastar la información para corroborar la localización indicada por el epigrafista alemán (Morena y Sánchez 2011: 135. Román y Ruiz 2009: 14. Ordóñez y Ruiz 2015b).

Esta misma procedencia tan poco explícita la encontramos en trabajos que van desde el de Fidel Fita (1908: 351), hasta el de Enrique Ruiz Prieto sobre las placas decoradas existentes en el Museo Arqueológico de Sevilla (2012: 15), pasando por el de José Vives (1969: 138) o por el catálogo elaborado por E. Serrano y R. Atencia de las depositadas en el Museo de Málaga 


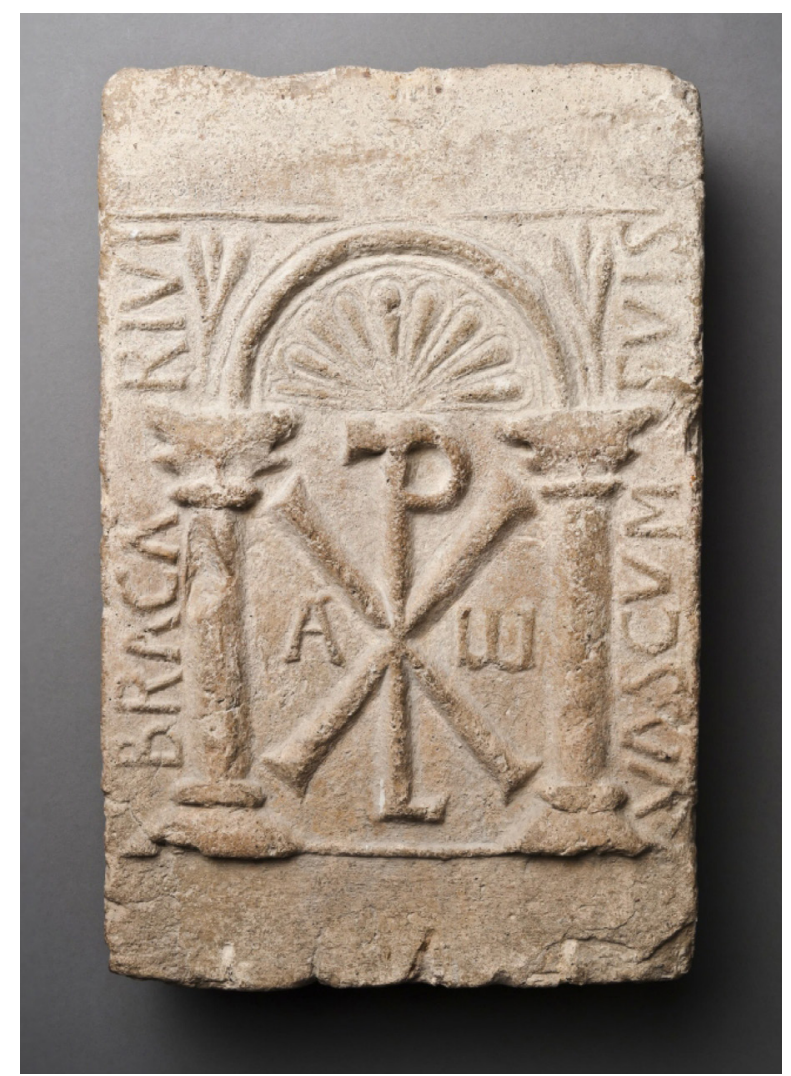

Figura 4. Bracario del Museo Arqueológico Nacional. Imagen tomada de su ficha en Ceres.es (http://ceres.mcu.es/pages/Vie wer? accion $=4 \&$ AMuseo $=$ MAN $\&$ Ninv $=50077$ ).

(Serrano y Atencia 1981). Pero además de esta coincidencia geográfica, estos trabajos comparten otro denominador común que también es extensible a la mayoría de los demás estudios, cual es el de señalar Ronda o la zona de Ronda como lugar de procedencia de los ejemplares conocidos. En este grupo encontramos el grueso de los trabajos pues, aparte de los ya citados, habría que incorporar por orden cronológico el de Manuel Rodríguez de Berlanga, sobre los existentes en la colección Loringiana, que son los mismos que los depositados en el Museo de Málaga, y que dice son de Ronda (Rodríguez de Berlanga 1903: 130), al igual que lo hacen sobre estos ejemplares tanto Simeón Giménez Reyna como María Luisa Loza (Giménez Reyna 1946: 106, Loza Azuaga 1991-92: 259), el primero de estos dos autores concretando incluso su origen dentro de la zona de Ronda (el Cortijo de la Vizcondesa). Por último estaría el ejemplar que incorporan Camps Cazorla y José Ferrandis en sus respectivos capítulos de la Historia de España de Menéndez Pidal, procedente del Museo Arqueológico Nacional, del que especifican es de Acinipo
(Camps Cazorla 1940, Ferrandis Torres 1940); el mismo que reproducen H. Schlunk y T. Hauschild, del que dicen, sin embargo, que puede ser de Ronda (1978: 58).

De Ronda también son los ejemplares relacionados en los dos trabajos centrados con mayor concreción en la comarca, si bien uno de ellos no directamente relacionado con el tema. Se trata del trabajo de Alfonso Pérez Aguilar sobre el cortijo de la Vizcondesa (1966: 399) -en el que aparecieron los únicos ejemplares conocidos de la serie MAXIM (Gozalbes Cravioto 1987, Barroso y Morín 1994, Stylow 2005)- en el que ofrece el nombre de otro de los lugares de la depresión en donde aparecen estas placas, y apunta a la posibilidad de que algunas de ellas pudieran ser falsas; y del estudio de Sonia Ruiz, este sí centrado en la colección de este tipo de piezas decoradas conservada en el Museo de Ronda, entre las que se encuentran varios ejemplares de la serie Bracario (Ruiz Torres 2006).

De esta tónica general se salen algunos artículos que proponen o suman otras procedencias inéditas hasta el momento, pero que, precisamente por esta razón, no parecen muy fiables. Son los casos de Asta Regia (Esteve Guerrero 1941), cuyo ejemplar ya estaba desaparecido en el momento en el que se menciona; del ejemplar conservado en el Museo de Cáceres, donado a esta institución en el año 1951 del que "se ignoran otros detalles", y sobre el que hay que insistir en que no se ha vuelto a producir hallazgo alguno tras 70 años (Callejo Serrano 1962: 247); y del sector Cártama-Fuengirola como posible área de producción ejemplares de nuestra serie, propuesta para la que no encontramos base que la sustente, ya que no existe ninguna referencia a hallazgos de piezas similares en estas localidades, al menos que nosotros hayamos rastreado (Ruiz González 2014: 119).

Tampoco creemos que exista base alguna para establecer un área de dispersión menor de los tipos con crismón (suponemos que también de la serie que nos ocupa) en Málaga y Granada (Gómez de Avellaneda Sabio 2011: 532), cuando precisamente estamos viendo, solo atendiendo a la bibliografía, que el interior de la primera provincia constituye un posible ejemplo de irradiación. Así lo recoge en su trabajo el mismo Carlos Gómez de Avellaneda, al considerar las propuestas de un posible taller en el área de Ronda que se encuentran en trabajos de Schlunk (1944) o Palol (1956) (Gómez de Avellaneda Sabio 2011: 524). Sin embargo, paradójicamente, este mismo autor es el que, a raíz del fragmento que analiza en este artículo, por cierto también hallado sin contexto, y por tratarse de un fallo de alfar, termina sugiriendo que dicha irradiación se habría 
producido desde el área costera hacia el interior (Ibid.: 521 y 532). Es decir, que un fallo del alfar permite inferir fabricación en el lugar, y la presencia de varios ejemplares de la misma serie y con características formales similares no parece ser suficiente como para que pudiera haber existido un taller allí donde se concentran muchos de ellos. Pero encontramos un argumento más para dudar que dicha distribución se realizara en el sentido que se menciona. En la zona rondeña no se ha encontrado ningún ejemplar ni siquiera parecido al de Barbesula que, como es conocido, presenta invertido el anagrama de Cristo. Sin embargo, sí se ha hallado recientemente un fragmento similar en la cercana Estepona $^{1}$, lo que ofrecería una imagen más lógica de distribución comarcal, en la costa occidental de la actual provincia de Málaga. No encontrar ningún ejemplar de la serie Bracario allí, como ningún crismón reflejado en la comarca de Ronda, aunque sea descontextualizado, no haría más que incidir en la comarcalización de estos talleres en los que, obviamente, no solo se fabricarían placas cerámicas decoradas. En el sentido inverso se han manifestado otros autores que justifican la gran dispersión de ejemplares con la inscripción Bracario por la existencia de una importante red de comercialización, desde un centro productor indeterminado (González y Salvador 1997: 327). No obstante, nos inclinamos a pensar que tal distribución de ejemplares se produce en época reciente, posiblemente a partir del descubrimiento a inicios del siglo XVII del centenar de placas en Lagar de Peinado. La posibilidad de que hubiera existido este taller ha llegado a concretarse aún más con la propuesta del Cortijo de la Vizcondesa (Pérez Aguilar 1966 y Giménez Reyna 1946, citando a Félix Hernández que parece ser el autor de la propuesta, o la última referencia en este sentido recogida en Hanel y Ristow 2010: 307; también Martín Gómez 1982), o como resultado del mantenimiento de un artesanado vinculado a alguna ciudad (Salvador Ventura 1990: 412).

Para finalizar el apartado hay que citar el trabajo de Raquel Castelo (1996), el más completo sobre estos elementos cerámicos junto con otro más reciente de $\mathrm{J}$. I. Ruiz y J. M. Román (2015), y el primero en recopilar todo lo publicado sobre los mismos hasta la fecha de su publicación. En él se reiteran las procedencias que hemos mostrado aquí, y a él remitimos para completar los

1. Noticia de Diario Sur de 27 de noviembre de 2015, consulta electrónica en http://www.diariosur.es/marbella-estepona/201511/27/ hallan-estepona-placa-decorada-20151127200746.html, el día 12 de febrero de 2017. aspectos formales y descriptivos que se nos hayan podido pasar en el nuestro.

Como segunda precisión, lo visto en este bloque dedicado a la bibliografía en la que se ha tratado de alguna forma este tipo de placa cerámica, revela que su procedencia mayoritaria vuelve a ser la comarca de Ronda, concretamente el área de la meseta o depresión rondeña, pues de ella son todos los ejemplares conocidos depositados en diferentes instituciones, que son asimismo las muestras sobre las que se han elaborado los trabajos reunidos aquí. Cuando esta procedencia no es Ronda, simplemente se da por desconocida, no registrándose ningún caso en el que se indique para esos mismos ejemplares un origen diferente al propuesto.

\subsection{Placas cerámicas decoradas de la serie Bracario en colecciones y museos}

Siguiendo el rastro dejado por las publicaciones anteriores, y siendo conocedores de la existencia de más placas dispersas por el mundo, el tercer apartado que debíamos tratar por estar relacionado con el anterior era precisamente el que atañe a la localización de ejemplares de nuestra serie en las colecciones de instituciones museísticas. Pero no solo para comprobar hasta dónde ha llegado su dispersión y elaborar un listado de museos que tienen alguna, sino sobre todo para observar qué información poseen estas instituciones sobre ellas que sea de utilidad para despejar algunas de nuestras dudas.

Sin embargo, la escasa representación de estos objetos en sus colecciones y la dificultad de acceder a ellas, ha hecho que su repercusión en este trabajo sea desigual. No obstante, creemos que es suficiente para tener una idea de la potencial dispersión de la serie en la escala local. Los ejemplares de las instituciones públicas nacionales y extranjeras de los que nos hemos servido en este trabajo, se resumen en la tabla 1.

Dejando al margen otras consideraciones contenidas en las fichas a partir de las que hemos elaborado la tabla anterior, como son sus descripciones, técnica de elaboración, o cronologías, por ser reiterativas y no relevantes ahora en la exposición, lo primero que llama la atención es que de las 21 piezas repartidas por estas 15 instituciones (11 españolas, y 4 extranjeras; no contabilizamos aquí las del Museo de Ronda), 11 proceden de Ronda o de la zona, 8 son de origen desconocido, fundamentalmente porque su adquisición se realizó en un lugar diferente (Sevilla, Granada o Barcelona) y, en todo caso, sin que se incluyera esta información en la transacción (fig. 5); una se dice que es de Carmona, 
Tabla 1

\begin{tabular}{|c|c|c|c|c|c|}
\hline & Museo & Referencia & Dimensiones & Procedencia & Observaciones \\
\hline \multirow{14}{*}{ 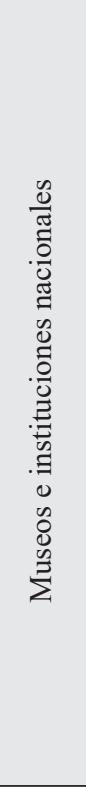 } & MAN & FA_FM_50077 & $32,7 \times 21 \times 5$ & Acinipo & \\
\hline & \multirow{5}{*}{ MMA } & $\mathrm{A} / \mathrm{CE} 13454$ & $32 \times 21 \times 5$ & Acinipo & Probable* \\
\hline & & $\mathrm{A} / \mathrm{CE} 02631$ & $22 \times 13 \times 5$ & Ronda & ¿Falsa? \\
\hline & & $\mathrm{A} / \mathrm{CE} 02634$ & $33 \times 21 \times 5$ & Ronda & \\
\hline & & $\mathrm{A} / \mathrm{CE} 02630$ & $20 \times 17 \times 5$ & Desconocida & ¿Falsa? \\
\hline & & $\mathrm{A} / \mathrm{CE} 02628$ & $32 \times 21 \times 5$ & Acinipo-Ronda & \\
\hline & MAECO & $\mathrm{CE} / 007001$ & $32 \times 21 \times 5$ & ¿Carmona? & $\begin{array}{l}\text { No hay noticias de ninguno hallado en } \\
\text { esta ciudad }\end{array}$ \\
\hline & MAEGR & $\mathrm{CE} / 04439$ & $32,5 \times 21,5 \times 5$ & Acinipo-Ronda & \\
\hline & MASE & ROD2655 & $32 \times 20 \times 5,5$ & Desconocida & Alta el 16/II/1946 \\
\hline & MUCC & CE002673 & $20 * x 21 \times 4,3$ & ¿Prov. Cáceres? & Donación en 1951 \\
\hline & MNCERAS & CE1/03194 & $32 \times 20,5 \times 4,5$ & Acinipo-Ronda & \\
\hline & MUHBA & MCB112808 & $32,5 \times 22 \times 5$ & Desconocida & Donación \\
\hline & \multirow{2}{*}{ GA-RAH } & RAH9-7580 & $31 \times 21 \times 5$ & Ronda & Moreti 1865 \\
\hline & & RAH9-7581 & $31 \times 21 \times 5$ & Ronda & Moreti 1865 \\
\hline \multirow{5}{*}{ 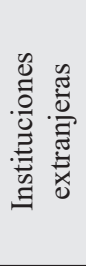 } & MET & 1985.147 & $33,3 \times 21 \times 6$ & Desconocida & Adquirido en Barcelona en 1926 \\
\hline & $\mathrm{BM}$ & 1889.0705 .1 & $32,5 \times 21,5 \times 5$ & Ronda & Probable \\
\hline & VAM & A. 62.1930 & $32,5 \times 21,5 \times 5$ & Ronda & Probable. Adquirido en Granada \\
\hline & \multirow{2}{*}{ SMBK } & 6112 & $32,5 \times 21 \times 5,3$ & Desconocida & Adquirido en Sevilla 1906 \\
\hline & & 6641 & $32,5 \times 21,5 \times 5,3$ & Desconocida & Adquirido en Sevilla 1910 \\
\hline \multirow{11}{*}{$\begin{array}{l}\frac{n}{0} \\
\frac{0}{\pi} \\
0 \\
0 \\
0 \\
0 \\
0 \\
0 \\
\tilde{z}\end{array}$} & MHMV & 606 & $33,3 \times 21 \times 5$ & Desconocida & Donación particular \\
\hline & CMB & $\mathrm{SI} / \mathrm{S} 3 / \mathrm{LD} / 14$ & $32 \times 21,5 \times 5 ?$ & Desconocida & Similar a la donada por Moreti RAH \\
\hline & \multirow{9}{*}{ MdR } & 0580 & $32,5 \times 21,5 \times 5$ & Ronda & Lagar de Peinado \\
\hline & & 0581 & $22 * \times 21 \times 5$ & Ronda & Lagar de Peinado \\
\hline & & 0582 & $20,5 * x 11 * x 5$ & Ronda & Lagar de Peinado \\
\hline & & 0583 & $19,5 * \times 12,5 * \times 5$ & Ronda & Lagar de Peinado \\
\hline & & 0584 & $21,5 * \times 21 \times 5$ & Ronda & Lagar de Peinado \\
\hline & & 0585 & $19 * \times 21 \times 5$ & Ronda & Lagar de Peinado \\
\hline & & 0586 & $19 * \times 21 \times 5$ & Ronda & Lagar de Peinado \\
\hline & & 0587 & $15 * \times 14,5 * 5,4$ & Ronda & Lagar de Peinado \\
\hline & & 0588 & $10 * x 9,5 * x 4,5$ & Ronda & Lagar de Peinado \\
\hline
\end{tabular}

Abreviaturas de las instituciones relacionadas: MAN = Museo Arqueológico Nacional; MMA = Museo de Málaga; MAECO = Museo Arqueológico y Etnológico de Córdoba; MAEGR = Museo Arqueológico y Etnológico de Granada; MASE = Museo Arqueológico de Sevilla; MUCC = Museo de Cáceres; MNCERAS = Museo Nacional de Cerámica y Artes Suntuarias González Martí (Valencia); MUHBA = Museu d'Història de Barcelona; GA-RAH = Gabinete de Antigüedades de la Real Academia de la Historia; BM = British Museum, Londres; VAM = Victoria and Albert Museum, Londres; MET = Metropolitan Museum of Art, Nueva York; SMBK = Skulpturensammlung und Museum für Byzantinische Kunst, Berlín; MHMV = Museo Histórico Municipal de Villamartín (Cádiz); CMB = Casa Museo Bonsor, Castillo de Mairena del Alcor (Sevilla); MdR = Museo de Ronda.

*Con esta pieza parece haberse producido un error de inscripción. En su ficha se indica que procede de las termas de Fuengirola y que fue depositada por Pedro Aguayo, cuando sabemos que las termas en las que intervino este investigador fueron las de Acinipo, lugar que encaja mejor con el tipo de placa. No es, en cualquier caso, el único error detectado en las fichas del Museo de Málaga sobre estas placas, ya que casi todas ellas tienen mal el campo de "descripción" y el de "inscripción/leyenda". 
aunque con dudas: figura con esa procedencia en su ficha del Museo de Córdoba, aunque una publicación referida a otros objetos visigodos en ese museo (De los Santos Gener 1958: 37) se mencionan una placa de la serie Bracario y otro ladrillo de tema geométrico (el conocido como "nudo gordiano"), ambos además ilustrados en la obra y el segundo de ellos procedente del Cortijo de la Marquesa en Ronda, lo que da pie a atribuir la misma procedencia a la placa, de la que no se dice expresamente que venga de Carmona. Por último hay otra, con dudas también, que podría proceder de la provincia de Cáceres. De todas ellas, una de Ronda y otra de las desconocidas pueden ser quizá falsas por los tamaños que presentan, y que se salen de la generalidad del resto.

Huelga decir que los ejemplares que se encuentran en el Museo de Ronda, nueve en total (una pieza completa, cuatro mitades y otros cuatro fragmentos), proceden de este municipio. Pero precisamente por ello se tendrán en cuenta en el apartado en el que trataremos las referencias arqueológicas.

La tercera precisión que podríamos inferir de lo que se ha expuesto en este apartado es que de las 30 piezas depositadas en museos, incluidas las del Museo de Ronda, 20 son de esta ciudad; o lo que es los mismo, que el $66,6 \%$ de ellas son de la zona de Ronda, mientras que el otro el $33,3 \%$ queda huérfano de lugar, pues a 8 placas no se les atribuye ninguna procedencia concreta, y las dos que quedan, de Carmona y Cáceres, presentan tantas dudas que lo prudente es incluirlas en este grupo.

\subsection{Referencias arqueológicas}

A lo largo del repaso que hemos realizado en el apartado inicial de este trabajo, en el que se ha ofrecido una visión general de la bibliografía que contiene referencias sobre estos elementos de la cultura material de la Antigüedad tardía, se ha podido comprobar cómo loas ejemplares de la serie Bracario no están presentes en ninguno de los casos considerados, salvo en los relacionados con Ronda, y en la más que dudosa excepción del conservado en el Museo de Cáceres. Por ello, no sabemos muy bien en qué momento se genera el rumor sobre posibles hallazgos de esta serie en diferentes lugares de la Bética que, a pesar de su inconsistencia, ha terminado por consolidarse como una certeza sobre la que nadie ha planteado la más mínima duda. Y eso que en los mismos trabajos en los que no se cuestiona esta dispersión, se insiste en el escaso valor probatorio que supone no contar con contextos arqueológicos. Pero tampoco esto es

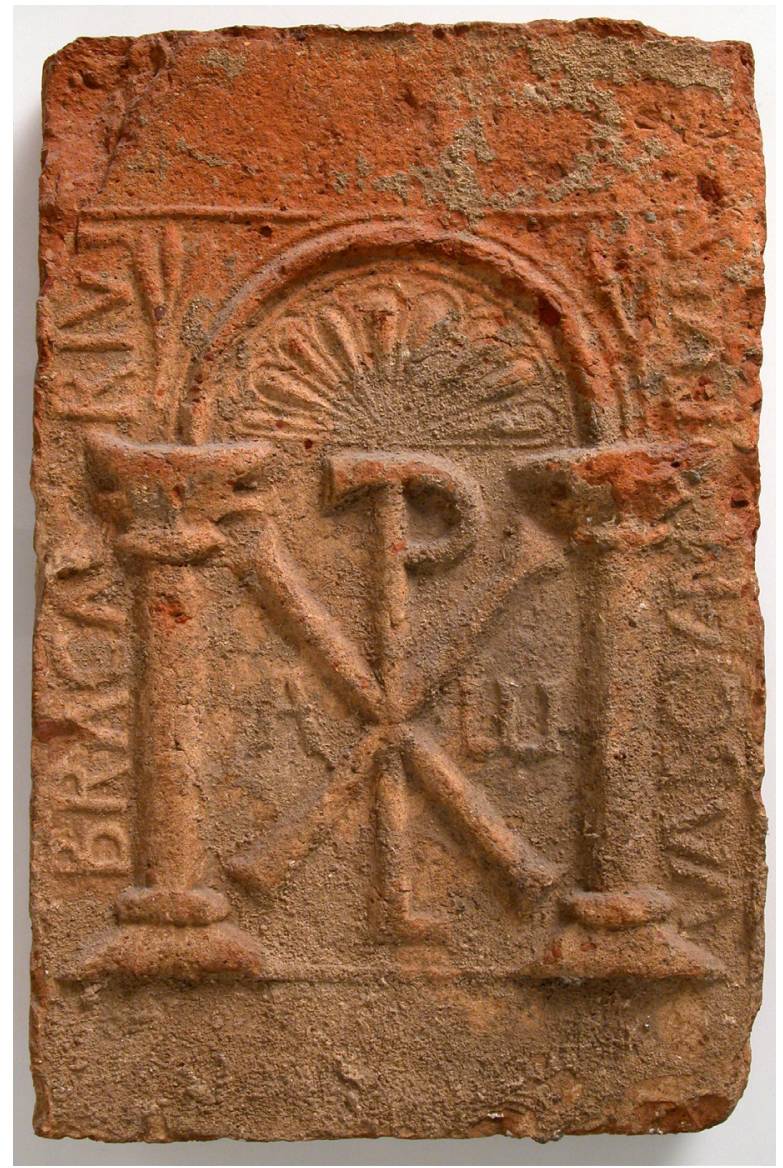

Figura 5. Bracario del Metropolitan Museum of Art de Nueva York (https://www.metmuseum.org/art/ collection/search/466122).

del todo verdad, pues ya existían trabajos en los que se señalaba la localización de placas cerámicas de Bracario en registros arqueológicos superficiales (Ruiz Torres 2006: 102) que, aunque con un marcado carácter diacrónico, no dejan de ser contextos susceptibles de ser investigados por una rama de la Arqueología que ha tenido, tiene y tendrá un papel primordial en la investigación de la cultura material y de las sociedades del pasado junto a la arqueología de excavación: la prospección. Y al margen de interpretaciones o posibles errores acumulados por una historiografía que se reproduce de forma reiterada y a la que se incorporan errores nuevos, una cosa sí que es clara: que frente al rumor o a la duda, está la prueba del hallazgo documentado.

Por ello este bloque dedicado a los ejemplares de la serie Bracario quedaría incompleto de no contemplar las referencias arqueológicas que tenemos sobre estas piezas, que no por ser escasas poseen un interés 


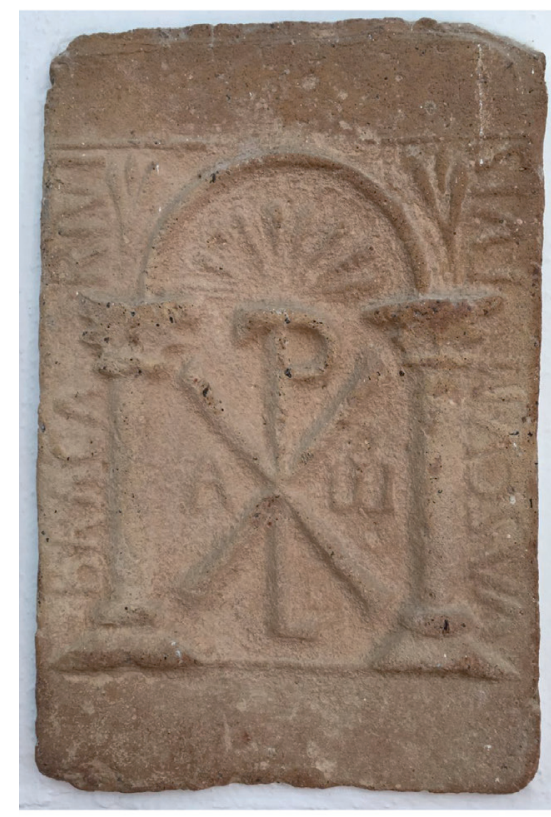

Calle Capitán Cortés (Ronda)

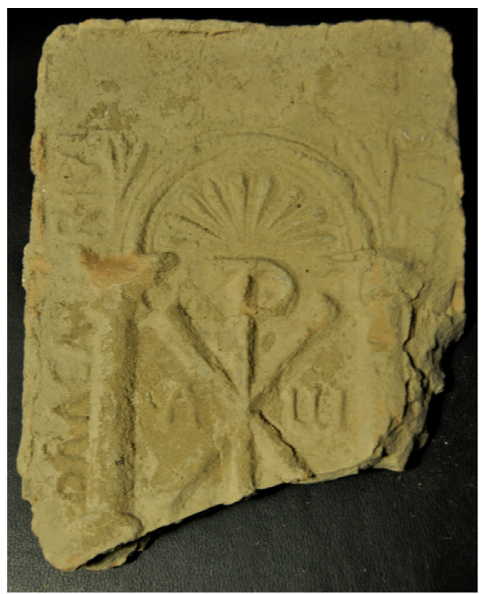

El Majuelo (Ronda)

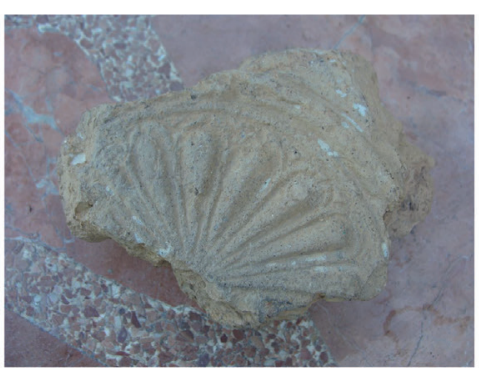

Parauta

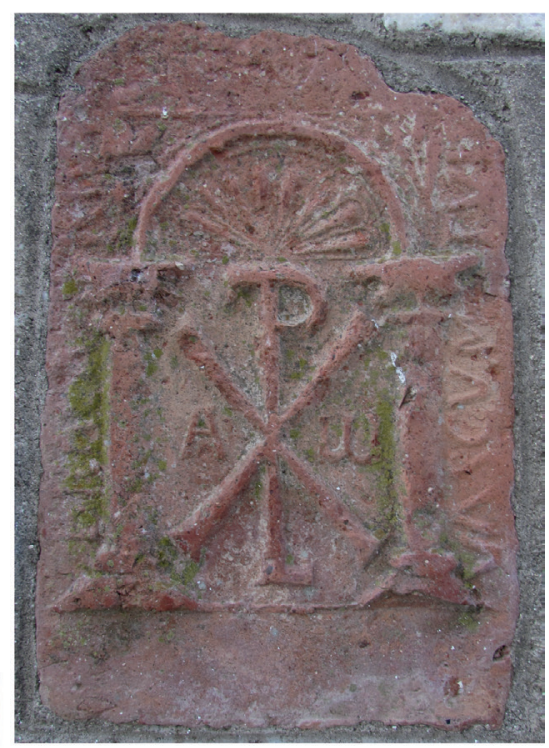

El Fuerte (Ronda)

Figura 6. Bracarios procedentes de Ronda en colecciones particulares.

menor. Como se ha dicho, a pesar de contar con algunos contextos estratigráficos cerrados (útiles entre otras cosas para la atribución de cronologías más ajustadas y contrastables), que, sin embargo, ofrecen no pocas dudas, estos no son los únicos existentes que permitan extraer conclusiones, pudiéndose por tanto inferir consideraciones al respecto, tanto a partir de la información proporcionada por otras técnicas y estrategias de investigación arqueológica, como por la información indirecta de carácter oral originada con ocasión de algún hallazgo casual, o la que nos ofrecen otras fuentes documentales como las escritas. A estas últimas pertenecen tanto la noticia relativa al descubrimiento en el primer tercio del siglo XVII de un buen número de ejemplares del que da fe Diego de Maraver, como la del hallazgo de Benaoján citado por Medina Conde a finales del siglo XVIII. En cuanto a los ejemplares pertenecientes a informantes que han sido protagonistas o destinatarios de algún hallazgo casual, contamos al menos con tres casos: uno de Ronda, completo, descubierto durante unas obras de reforma de una casa en los alrededores de calle Puya (hoy Capitán Cortés); un fragmento encontrado por su propietario en una finca del paraje conocido como El Majuelo, próximo al Cortijo de la Vizcondesa, al que nos hemos referido en varias ocasiones; y por último un pequeño fragmento de la venera, quizá de una de estas piezas, encontrado en unas obras de una calle de Parauta. Este trozo de placa junto con la encontrada en Ronda, que no fue la única, solo sirven para certificar el reempleo de estos objetos como material de acarreo, una práctica por otra parte muy común en cualquier época pero que, de forma particular, tenemos atestiguada para estos materiales (Moreti Sánchez 1867: 151, nota). Por último estaría el que hoy se encuentra empotrado en un pequeño pretil de la zona conocida como El Fuerte, también en Ronda. Aunque desconocemos su procedencia con más exactitud, su origen rondeño está claro (fig. 6).

En cuanto a las estrategias de investigación arqueológica, la más desarrollada en nuestro caso ha sido la prospección superficial, ampliamente practicada en el marco tanto de proyectos de investigación como de trabajos de gestión patrimonial. En el transcurso de ellos se ha recuperado material de superficie fragmentado de 
esta serie de placas, así como de otras, que son las que forman parte de la colección del Museo Municipal. Son ocho fragmentos de piezas de Bracarios -pues la completa, aun cuando procede de una donación por parte de quien la encontró de forma directa, no ha sido recogida por nosotros (fig. 7)-, halladas en dos villae tardoantiguas de las que tenemos documentadas en el término de Ronda, ambas además ya citadas en este trabajo; Lagar de Peinado y Cortijo de la Vizcondesa (fig. 8).

Desgraciadamente, estas referencias no se encuentran respaldadas de momento por cronologías más o menos precisas, ya que en el caso de estos asentamientos, y ante la inexistencia de excavaciones, la información viene proporcionada por sus contextos de superficie. Estos solo sirven para establecer fechas basadas fundamentalmente en las cerámicas correspondientes con las vajillas de lujo, como ARSW, lo que dada la perduración del algunos de sus tipos y, sobre todo, su ausencia aun cuando el asentamiento continúa siendo utilizado, resulta poco esclarecedor. Sin embargo, sí que han sido relevantes estos hallazgos para poner en duda la procedencia de la vecina ciudad de Acinipo de algunos de los ejemplares conocidos, dado que en los alrededores de este yacimiento (tal vez la zona más intensamente prospectada de la depresión) curiosamente no se ha documentado ninguno. Un hecho bastante singular, si se tiene en cuenta que esta ciudad romana fue objeto de atención desde fechas tan tempranas como la de la noticia que da Diego de Maraver sobre el hallazgo de estas placas (1610), pues fue él precisamente uno de los pioneros en abordar el estudio de esta antigua urbe.

A pesar de no poder proponer una cronología basada en estratigrafías arqueológicas, y a la luz de la bibliografía generada tanto sobre estas, como sobre las demás placas cerámicas con simbología cristiana que hemos tenido ocasión de repasar más arriba, de lo que no cabe duda es de que una de las placas decoradas con crismón mejor documentadas arqueológicamente son las de la serie Bracario, lo que además ha permitido acotar espacialmente su lugar de procedencia a los alrededores de la ciudad de Ronda. Pero de esta circunstancia podemos inferir algo más, ya que si ponemos este hecho en conexión con otros ejemplos en los que el hallazgo de una cierta cantidad en prospección, caso de Morón en el yacimiento de Balbuan (Vera Reina 2000: 41), o de algún fallo de alfar, como en Barbesula, ha derivado en proponer en esos mismos lugares el posible taller en el que habrían sido fabricadas, las antiguas propuestas que situaban un taller en Ronda cobrarían aún más sentido. Esta sería, por tanto, nuestra última apreciación sobre estos cuatros aspectos relacionados con la serie.

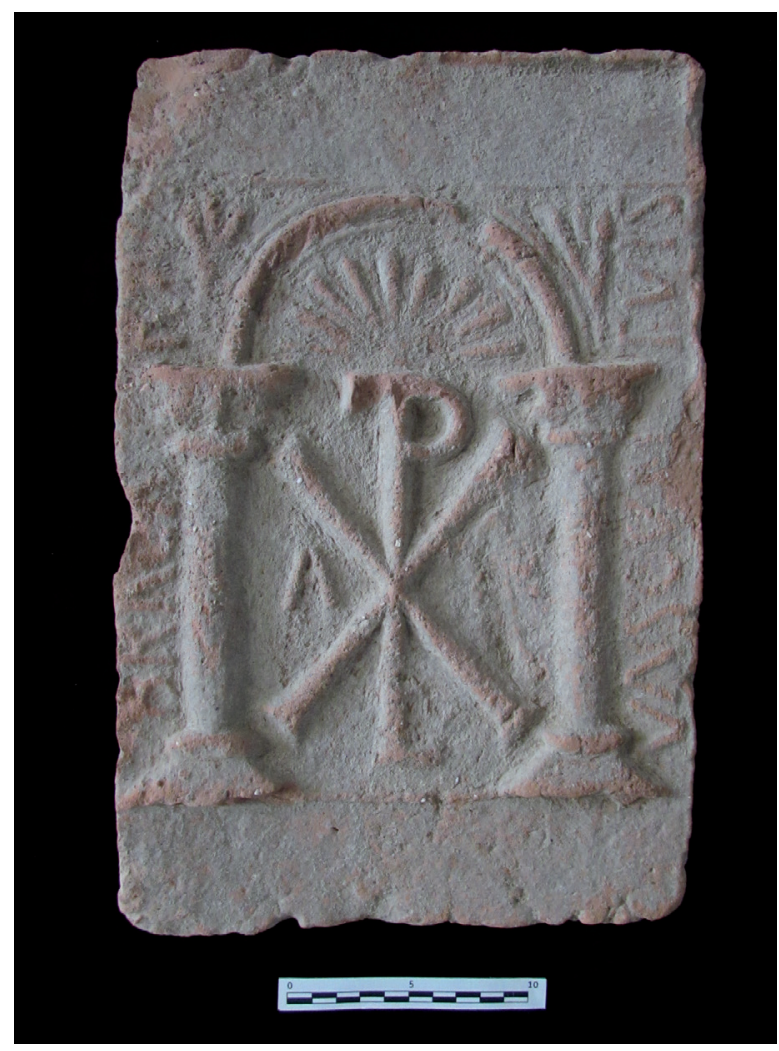

Figura 7. Bracario de Lagar de Peinado (MdR, 0580). Donación de D. Miguel Ángel Moscoso.

\subsection{Características morfológicas}

Para terminar el epígrafe, y de forma sucinta, vamos a considerar una de las cuestiones que más información nos puede ofrecer acerca de esta serie: sus características morfológicas. Aparte de la composición que define a nuestra serie (crismón, inscripción, etc.), las posibilidades que proporciona el análisis morfológico para caracterizar arqueológicamente este elemento resultan incuestionables a la hora, por ejemplo, de establecer paralelos con las demás piezas para procurar determinar si el taller en donde se pudieron fabricar fue también el mismo, toda vez que se podría considerar la existencia de uno en nuestra zona de estudio. Desgraciadamente no conocemos ese alfar o tejar, pero sí que podemos establecer semejanzas entre las piezas que existen con el objeto de poder despejar la posibilidad de que existiera más de un taller, ya que en poderse probar o no esta circunstancia se centra parte de la cuestión de que existieran distintos focos de producción de la serie.

Un simple análisis visual es suficiente para detectar semejanzas que van más allá de las propias similitudes 

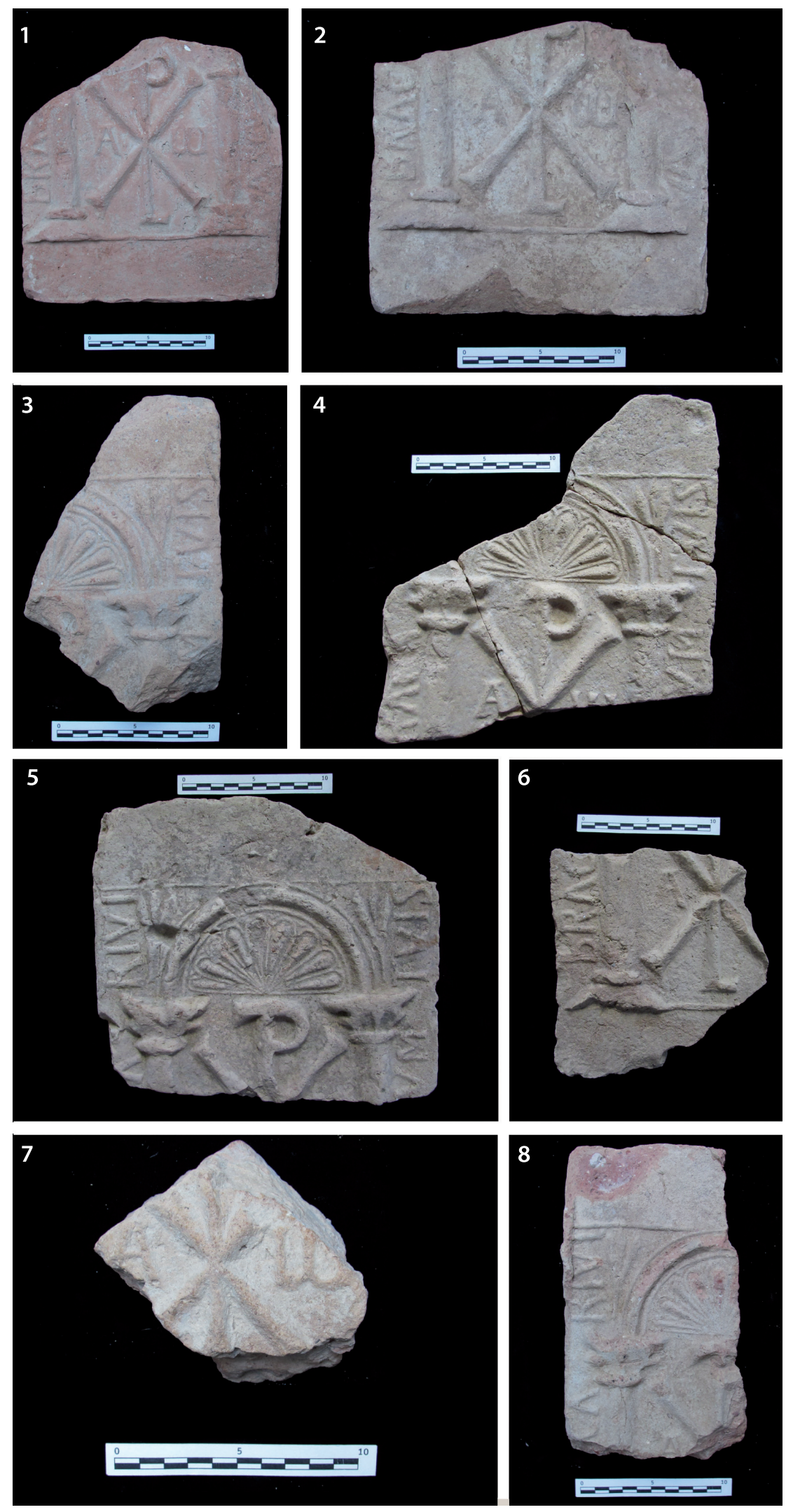

Figura 8. Bracarios de Ronda depositados en el Museo

Municipal.

1. MdR, 0584,

2. $\mathrm{MdR}, 0585$,

3. $\mathrm{MdR}, 0583$,

4. MdR, 0581,

5. MdR, 0586

6. MdR, 0587,

7. $\mathrm{MdR}, 0588$,

8. MdR, 0582 
observadas en el uso de los diferentes iconos que componen la placa. Y para enfatizar sobre estas semejanzas, vamos a mostrar primero las que son evidentes en todos los ejemplares que hemos analizado en este trabajo, para terminar ofreciendo algunas medidas internas (esto es, no las relativas a sus tres dimensiones) referidas a los ejemplares conservados en el Museo de Ronda pero que, dada la uniformidad que presenta el modelo, podrían hacerse extensibles a los demás. Pero a la luz de lo observado, y dada la señalada regularidad de la serie, estamos convencidos de que no encontraríamos variaciones sustanciales en la aplicación de tales medidas.

Las características comunes que comparten todos los ejemplares de placas cerámicas de la serie Bracario podrían ser muchas, pero a nuestro entender son cinco las que más llaman la atención:

a) Los capiteles de las columnas que enmarcan el crismón presentan en sus respectivas caras interiores dos muescas o mellas, también presentes en las exteriores aunque menos pronunciadas, así como un pequeño resalte intermedio que vendría a completar lo que parece ser la esquematización de un capitel corintio (fig. 9a).

b) La Alfa tiene un apéndice en su vértice superior, mientras que en la Omega es característico que su mitad derecha sea más ancha que la izquierda (fig. 9b).

c) Todas las veneras cuentan con nueve gajos, de los que el primero por la izquierda es más estrecho que los demás (fig. 9c).

d) La Ro del crismón presenta dos refuerzos sobresalientes en sus extremos superior e inferior (fig. 9d).

e) Por último, la inscripción que enmarca el motivo central comienza con la B de "Bracari" por encima del toro de la columna de la izquierda, y continúa con la V de "vas" inscrita en el eje del toro de la columna derecha (fig. 9e).

A estas semejanzas hay que sumar las relativas a la homogeneidad métrica que presentan los ejemplares, y que únicamente hemos podido comprobar en los depositados en el Museo de Ronda (fig. 10).

De lo expuesto en este último apartado, se podría deducir que el origen de todas los ejemplares conocidos de la serie apunta también hacia un único molde, lo que haría más creíble la posibilidad de que existiera un solo taller, y de que este, además, se encontrara en la zona de Ronda, habida cuenta del número de ejemplares que proceden de aquí según creemos haber podido evidenciar.
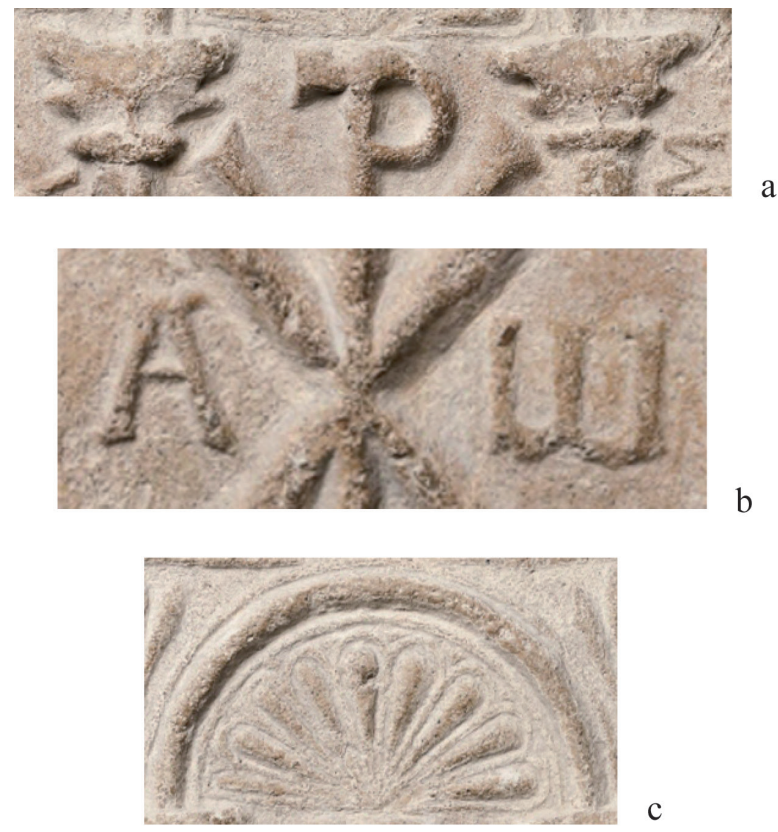

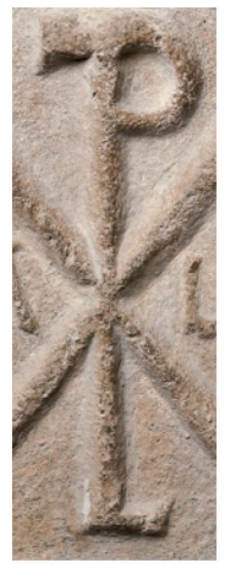

d

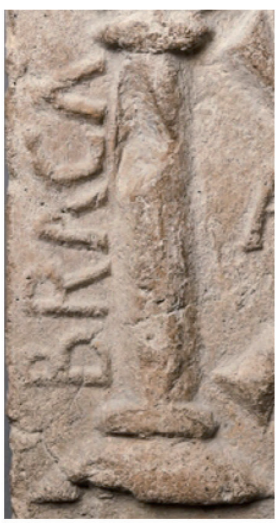

e

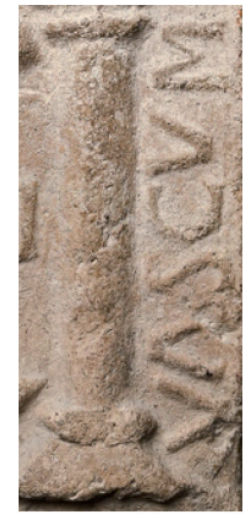

Figura 9. Características morfológicas compartidas por la serie Bracario.

\section{BRACARIO Y LA ARISTOCRACIA TARDOANTIGUA}

¿Y quién pudo ser el tal Bracario por cuyo nombre conocemos a esta serie de placas decoradas? Resulta tentador pensar que pudo tratarse de un personaje de una cierta relevancia, por lo que sus vínculos con las clases altas habría casi que presuponerlos. Por tanto, es también tentador pensar que no fuera cualquiera el que dejara registrado su nombre sobre un soporte como este, por muy barato que debiera costarle al ser un elemento realizado con un molde y, por ello, 


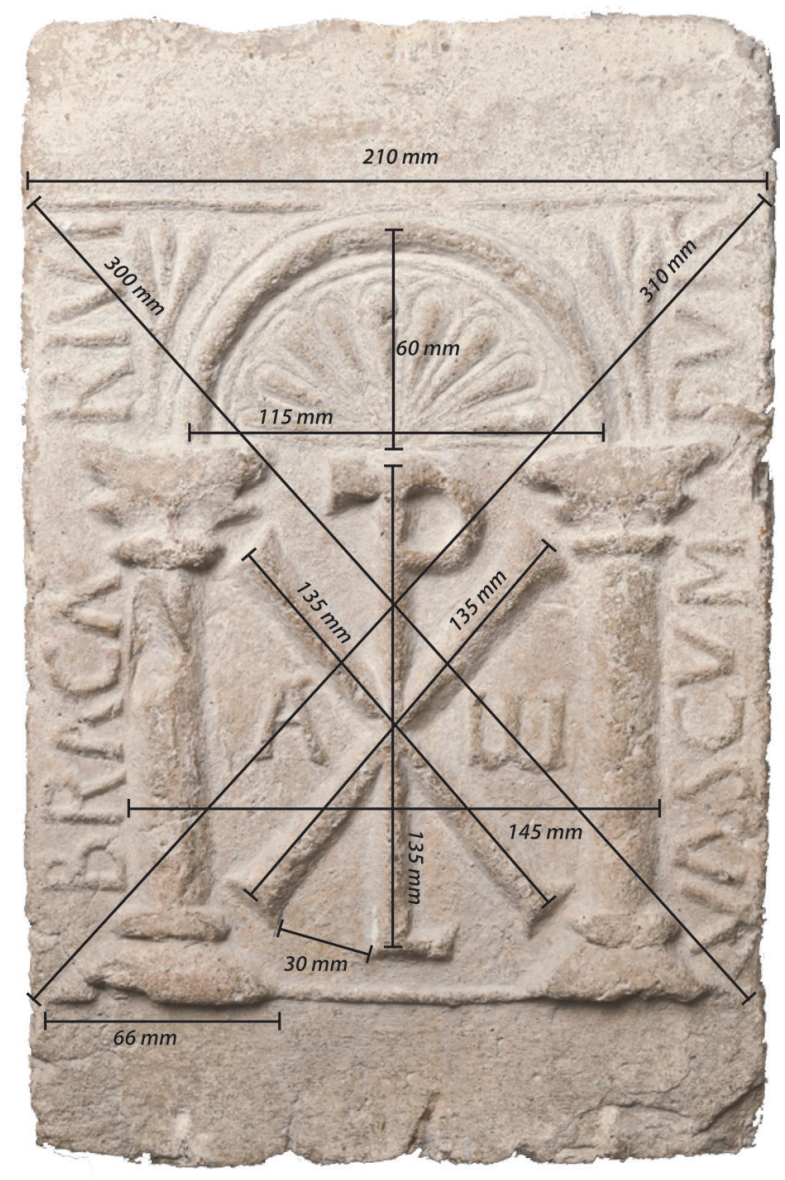

Figura 10. Referencias métricas de los ejemplares del Museo de Ronda.

relativamente estandarizado, incluido su fabricante, de los que también hay ejemplos como Leonti (CIL II 4967,38 = IHC 201 = CIL II2/7, 698; CIL II, 4967,39a $=I H C 202=C I L$ II2/5, 513a; CIL II 4967,39c $=C I L$ II2/5, 513c; CIL II2/5, 513, d, e, f ), o el figulus Restitutus (CIL II2/7, 87a) (Ordóñez y Ruiz 2016). Tanto es así, que solamente se conocen dos personas con este nombre en el cuerpo epigráfico que se ha conservado de la península ibérica: una del siglo IV y otra del VII. La primera de ellas $(I H C 331=I L C V 2832=$ ICERV 18) se refiere a un hombre natural de Emerita que murió a los 52 años de edad en el año 381 (Solano Gálvez de San Pelayo y Villalpando 1897: 403). Eso es todo. No hay más referencias sobre él. Se trata además de su lápida sepulcral por lo que solo hay un ejemplar, lo cual abre la posibilidad de que no necesariamente tuviera que ser alguien con posibles. La segunda persona a la que se podrían vincular nombre y soporte cerámico fue un obispo que ocupó la sede hispalense en el tercer cuarto del siglo VII, del que existen algunas noticias o referencias más que del anterior.

Este Bracario fue obispo de Sevilla entre los años 657 y 680 , esto es, en el periodo comprendido entre su antecesor Fugitivo y su sucesor Julián, ambos participantes en los Concilios X y XII de Toledo (en 656 y 681 respectivamente). Veinticinco años en los que la silla episcopal debió estar ocupada por alguien. Que la correspondencia con ese alguien fuera Bracario se debe en parte al padre Flórez, quien a raíz de la documentación de este nombre en el Episcopologio Emilianense de El Escorial, estableció esta posible conexión, añadiendo alguna apreciación más sobre el personaje, como fueron sus dotes como escritor en materias dogmáticas (Flórez 1752, t. IX: 220; Sotomayor Muro 2002: 472).

Parece existir cierto consenso en señalar la más que posible pertenencia de este personaje a la aristocracia del momento, pues la documentación disponible hoy en día tiende a confirmar que este tipo de fórmulas nominativas empleadas en placas cerámicas o en otros soportes estaban reservadas en la Antigüedad tardía a personajes ilustres, entre los que por supuesto se encontraban los obispos (Di Stefano Manzella 2012: 244. Hanel y Ristow 2010: 307). Es un clásico en la investigación de este periodo tardío la figura de los obispos constructores de iglesias que proceden de los potentiores, esto es, de las aristocracias principalmente locales (Sotomayor Muro 2002: 250). Que fueran estas aristocracias quienes fomentaran la creación de centros de culto cristiano es algo asumido generalmente (Castillo Maldonado 2005, Castillo Maldonado 2013), incluso en lo que se refiere a su repercusión en los medios rurales, aunque haya que retrasar algo las fechas en las que se observa esta tendencia para que se pueda detectar arqueológicamente, como sostiene A. Chavarría (Chavarría Arnau 2006: 203). Que la presencia de edificaciones religiosas en los medios rurales se debiera además a estas personas, miembros destacados de la sociedad, no debería extrañar igualmente, ya que gran parte de la riqueza alcanzada por estas clases se basaba precisamente en la posesión de tierras, que en ocasiones podían llegar a alcanzar extensiones considerables y localizaciones variadas (Wickham 2008: 240). Una circunstancia temporal a la que habría que sumar otra de carácter espiritual, como era la profesión de unas convicciones religiosas realmente profundas que llegaron incluso a trastocar la manera en la que se venían manifestando públicamente las capas sociales 
más altas, cada vez más alejadas del exhibicionismo romano clásico (Castillo Maldonado 2005: 350). Aunque esto no signifique que se rehuyera el efecto que conseguía el promotor al fundar una iglesia de consolidar y perpetuar también su memoria (Castillo Maldonado 2005: 340), sobre todo en sus dominios, o de cristianizar a los rustici; acción que se encontraba entre las tareas pastorales propias de toda dignidad episcopal (Chavarría Arnau 2006: 206-208).

Esto no implica necesariamente que quien construía a su costa la iglesia tuviera que ser la misma persona que aparecía en la intitulación de la placa, pues entre las opciones de piezas de este tipo con nombres propios encontramos algunas con dos, lo que se ha interpretado como un gesto de asociar el nombre del donante al personaje a quien se dedica la obra (serían los casos de Asella con Himerio o de Optata con Isidoro); o en los casos en los que aparece un solo nombre, que el donante se hubiera mantenido en el anonimato. En cualquier caso parece que tales objetos, consideradas como "instrumenta domestica”, podrían ser dedicatorias realizadas tras la muerte de estos personajes. Unas personas que habrían recibido el orden episcopal, y que habrían tenido una relación especial con el lugar en donde se les dedica un templo, hubiera habido o no intermediación de algún donante (Castillo Maldonado 2005: 346).

Parece claro, pues, que nuestra propuesta en relación con este personaje se inclina hacia el Bracario obispo; un obispo que, como sus homólogos Marciano o Isidoro, pertenecería a la aristocracia tardoantigua que tenía en la jerarquía eclesiástica una forma segura de garantizar sus posesiones y privilegios; o lo que es lo mismo, de hacer carrera política como epígonos lejanos de los que en alguna ocasión practicaron el viejo cursus honorum, inactivo desde hacía tiempo (Castillo Maldonado 2013: 289). Y si bien hubo un Marciano que fuera obispo de Sevilla en el siglo V (además del que hubo en Écija en el VII) (Fita 1908: 353, Gómez-Moreno Martínez 1966: 111), obispos llamados Bracario o Isidoro solo parecen documentarse en el siglo VII (González Fernández 2003), por lo que no resultaría descabellado estimar que esta moda de imprimir su nombre sobre placas cerámicas o ladrillos fuera compartida, y hasta cierto punto implantada, por estos hombres de iglesia, o por sus fieles más allegados (Castillo Maldonado 2013: 299, Stylow 1997, Hispania Epigrafica 1998: 65).

\section{BRACARIO Y LA DEPRESIÓN DE RONDA EN ÉPOCA TARDOANTIGUA. EL CONTEXTO}

En lo que llevamos expuesto se pueden apreciar de forma clara dos cuestiones que, relacionadas entre sí, dan pie a la formulación de una propuesta que en parte ya avanzamos hace muy poco tiempo, a saber: que el territorio en donde se registra la aparición de placas decoradas de Bracario está en la meseta de Ronda, y que el personaje aludido en tales soportes podría ser el obispo sevillano de la segunda mitad del siglo VII. A continuación pretendemos dar un pequeño paso más y mostrar el contexto en el que creemos que se puede inscribir este fenómeno, que no deja de ser particular; pues particular nos parece la llamativa concentración de esta serie en el área rondeña. La definición misma del fenómeno ya nos parece sugerente, pues de lo que hablamos es de vincular al tal Bracario con la aristocracia rondeña de época tardoantigua, y con la especial efervescencia que en esta zona tendrá el cristianismo tal vez como consecuencia de esta relación. Pero además también nos parece sugerente ante la aridez de referencias escritas y epigráficas que se tienen de esta zona para estos momentos, ya que esta probable relación constituiría un "unicum" en la investigación de la Antigüedad tardía no sólo de la Serranía de Ronda, de la que sería desde luego un caso excepcional, sino de buena parte de la Bética.

La drástica reducción de las unidades de poblamiento rural del tipo villa, que se inicia en época bajoimperial y se documenta en buena parte en la mitad occidental del Imperio, llega a su máxima expresión entre los siglos VI y VII, cuando de ellas únicamente quedan unos cuantos ejemplares. Ronda y su área no será un caso excepcional (fig. 11). De hecho, aquí se da la circunstancia de que esa reducción, $\mathrm{o}$, si se prefiere, concentración de población en unas cuantas unidades de poblamiento se verá acompañada por un trasvase del lugar de influencia que, hasta entonces, había estado representado por la principal de las ciudades de la comarca, Acinipo. Ahora, y sin que en este basculamiento se pueda suponer sustitución alguna en el carácter que como ciudad había tenido aquella, será Arunda la que asuma mayor protagonismo, aunque más que de este asentamiento habría que hablar de su territorio circundante, de su área de influencia, si es que alguna pudo ejercer una antigua y pequeña ciudad que en estos momentos seguramente solo conservaba como tal el nombre o su recuerdo (Castaño Aguilar 2005). Sea como fuere, lo que pone de manifiesto la investigación arqueológica que hemos desarrollado tanto en esta ciudad como en sus alrededores, es 

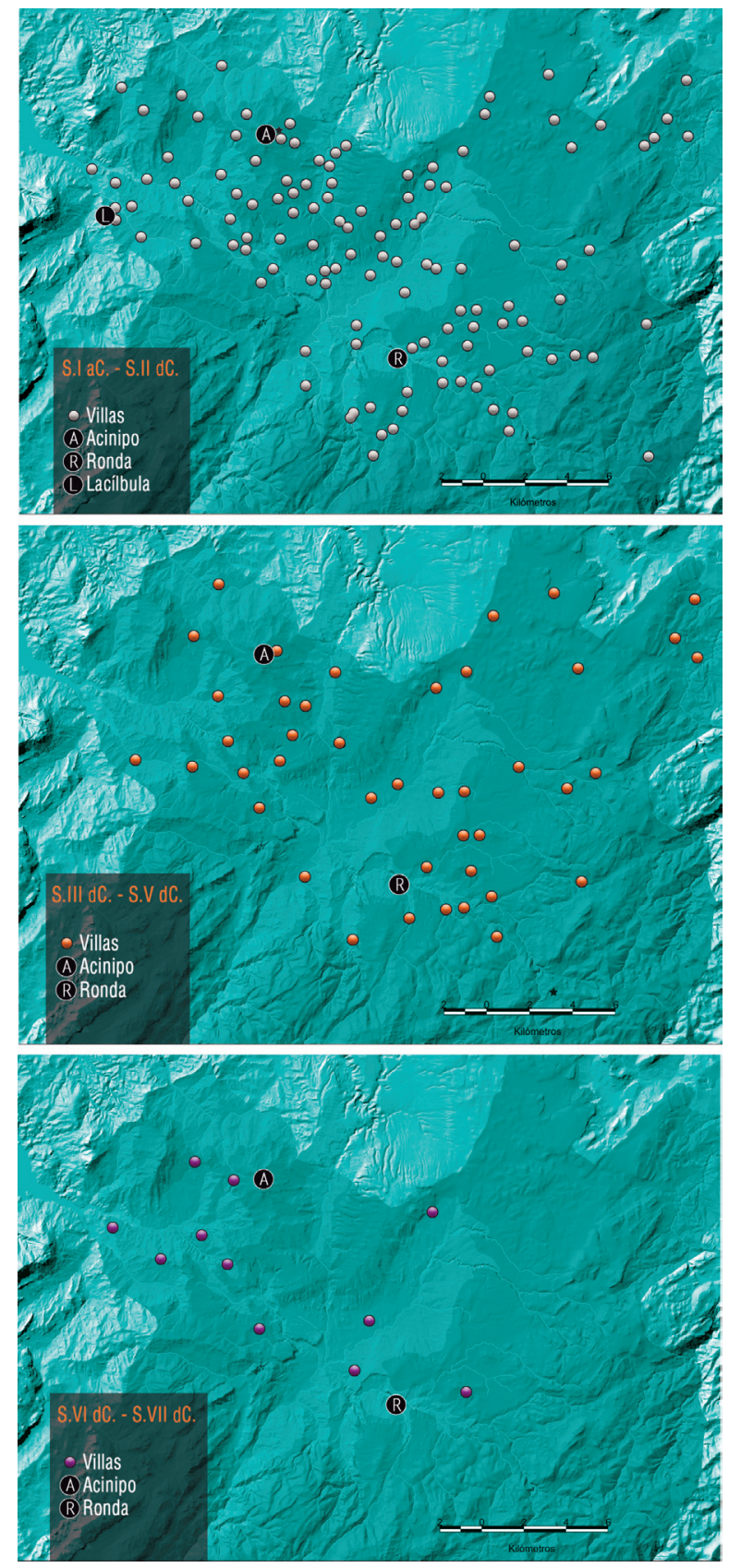

Figura 11. Evolución del poblamiento romano en la meseta de Ronda.

que las unidades de poblamiento rural que perviven, y que casi con seguridad rebasan el siglo VII, y algunas incluso el VIII, se localizan en el entorno de Arunda, a pesar de manifestar esta síntomas que harían de ella una villa (¿un vicus quizá?) más del territorio, término convencional que empleamos en su día para incidir en el carácter no urbano del emplazamiento en estos momentos
(Ibid.: 35). De la docena de asentamientos en los que es posible establecer algún vínculo con el poblamiento inmediatamente anterior, si restamos aquellos cuya tradición no parece provenir del ámbito aristocrático, dadas las dimensiones que presentan, solo la mitad reuniría las condiciones para ser considerados establecimientos pertenecientes a la aristocracia local: condiciones tales como una extensión de sus restos en superficie superior a la hectárea, presencia de cerámicas finas, mármoles y, cómo no, algún que otro elemento significativo de la religión cristiana.

El proceso por el cual estos lugares se convierten en grandes explotaciones en manos de la aristocracia local, que hace de estas posesiones (la tenencia de tierras) su sostén económico y social, es algo que puede observarse de manera habitual en esta mitad del Imperio, convirtiéndose en la razón principal que vendría a explicar la reducción del número de asentamientos que comentamos antes (Wickham 2008: 555, Brogiolo y Chavarría 2008: 200, Leveau y Loïc 2008: 142).

En nuestro caso, esta tendencia hacia la acumulación de propiedades rurales parece gozar de una especial significación en el entorno de Arunda, ya que las villae más representativas de esa media docena se encuentran en este sector de la meseta de Ronda. Efectivamente, en el área de influencia de Acinipo (junto con Ronda, la otra zona de la meseta mejor y más intensamente prospectada) este tipo de establecimientos se da con menor profusión, una circunstancia que va en aumento conforme se van incorporando nuevos yacimientos al catálogo de los existentes en la comarca, curiosamente localizados casi todos en la zona de Arunda-Ronda. Sin embargo, al respecto tampoco sabemos, y difícilmente lo lleguemos a saber algún día, si algunos de estos terratenientes tendrían sus latifundios en los alrededores de aquella ciudad en cuyo ager se encuentran las mejores tierras cerealistas de la depresión, mientras que su residencia se localizaba en el nuevo sector en boga, como hemos propuesto en algún caso en relación a la especialización productiva a la que pudieron destinarse algunas de esas villae integradas en la misma propiedad fundiaria, en las que buena parte de los sectores residenciales pasaron a ser espacios subsidiarios del proceso productivo (Castaño Aguilar 2012). Hay que señalar sobre esto que son momentos en los que la misma evolución de la propiedad ha provocado un cambio sustancial en los conceptos y términos que la definen, encontrando por ejemplo que tanto el término villa como algunos de sus derivados, no definen ya únicamente el terreno en donde se reside y en el que se sitúa la misma propiedad que se trabaja, sino la totalidad de las propiedades pertenecientes a un mismo 


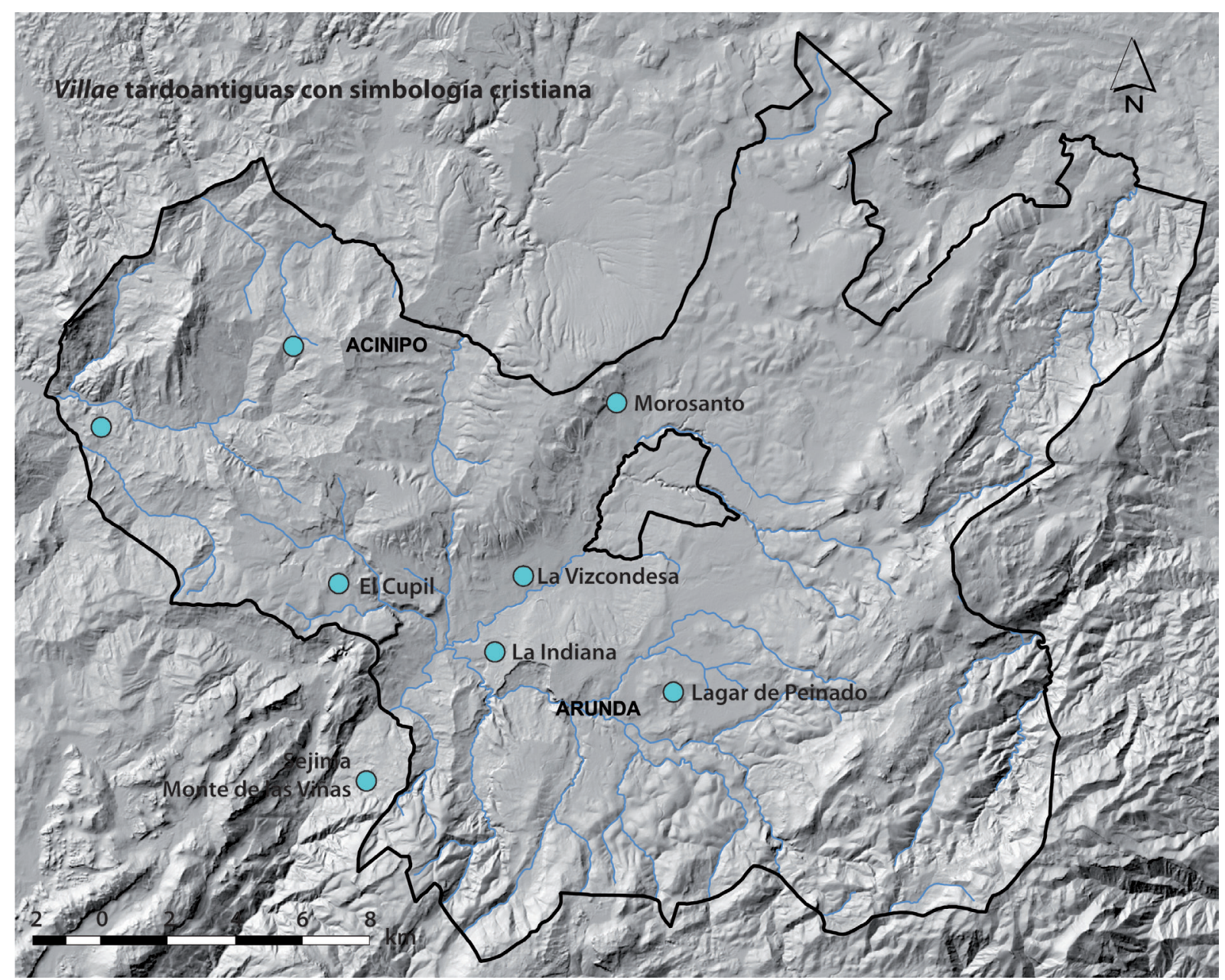

Figura 12. Villae tardoantiguas con simbología cristiana.

poseedor (Isla Frez 2001, Ripoll y Arce 2001: 22). Sea como fuere, no parece casual en el esquema observado en la meseta rondeña que el sector de Arunda sea el mejor representado por este tipo de centros productivos de cronología tardía, lo que cabría relacionar con dos acontecimientos o circunstancias a las que se podrían sumar también un par de elementos de la cultura material que se muestran igualmente con mayor claridad e insistencia en este ámbito: nos referimos al fenómeno cristiano y su impacto aquí, y al abandono de las residencias de estas grandes propiedades aristocráticas.

La introducción del cristianismo en nuestra comarca, particularmente en la meseta, parece haber ido de la mano de una élite local que lo adoptó y promocionó y que, en nuestro caso, fue esencialmente de carácter rural (Sánchez Ramos et al. 2015: 235). Un hecho generalizado en el que las clases altas de la sociedad romana se van cristianizando paulatinamente en un proceso complejo y lento cuyos efectos no parecen mostrarse de manera clara hasta avanzado el siglo V (Sastre de Diego 2012: 17). Esta relación entre clase aristocrática y nueva religión es especialmente visible en los lugares donde aquella fijaba su residencia, o en los que esta oficiaba sus rituales, cuyas evidencias en los registros de superficie o de excavación son más patentes. La localización de estos lugares en el estado actual de la investigación (que no pensamos que pueda verse modificado sustancialmente con la incorporación de nuevos elementos, al menos en lo que atañe a nuestra zona), parece haber tenido especial predilección por el área de Arunda, como venimos señalando, ya que son en los registros arqueológicos de esta antigua ciudad y de las villae tardoantiguas de sus alrededores en donde encontramos la mayor concentración de iconografía cristiana, además de otras instalaciones de carácter exclusivamente religioso (fig. 12). Ronda con su basílica, y quizá también los posibles eremitorios rupestres de la 

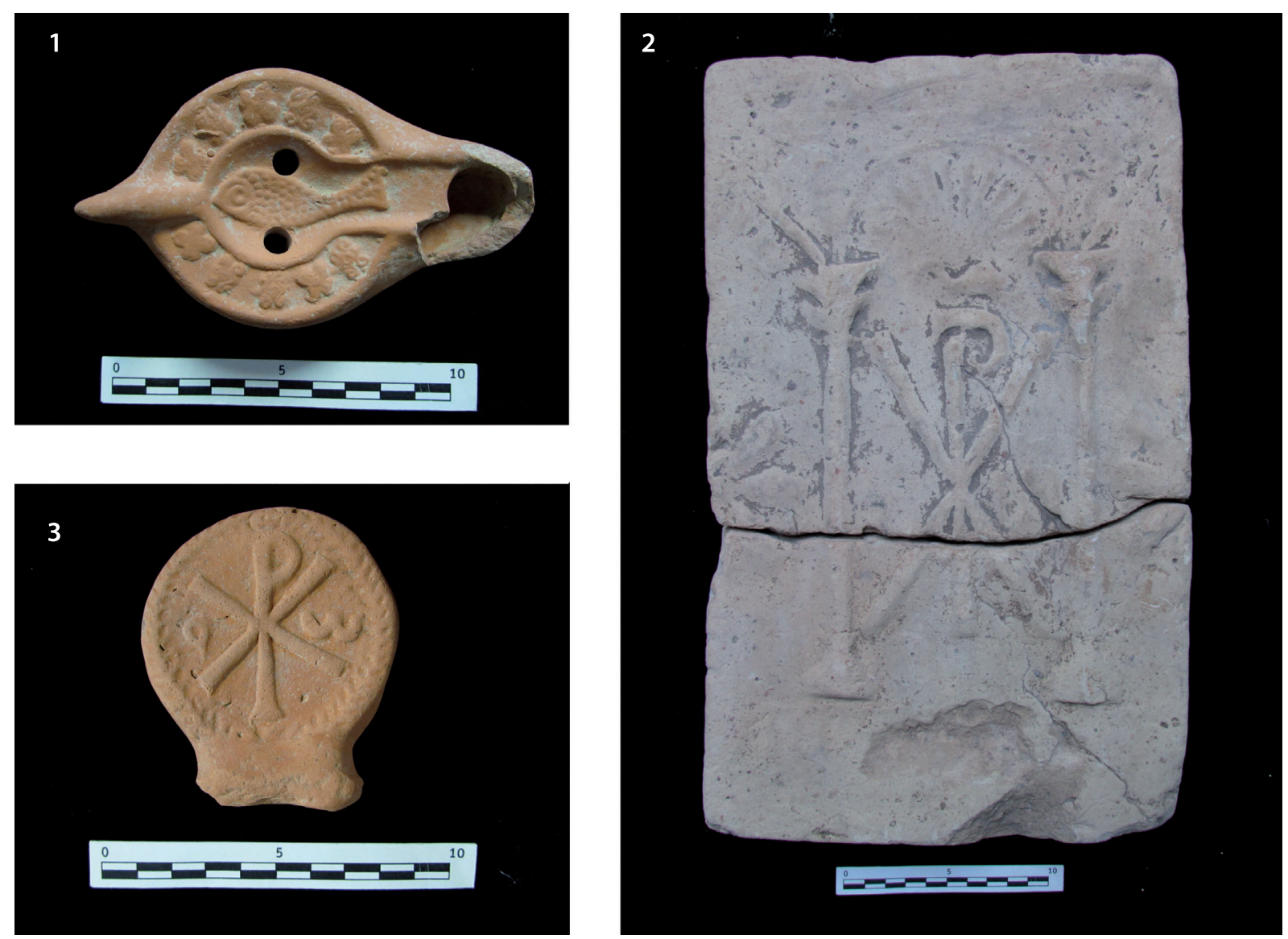

Figura 13. Otros materiales de iconografía cristiana hallados en los alrededores de Ronda. 1. Morosanto, RO-062-1; 2. El Cupil, RO-071-113; 3. La Indiana RO-063-1.

Virgen de la Cabeza y de la Oscuridad, podrían considerarse muestras de esos elementos especialmente dedicados al culto (Castaño Aguilar 2007), mientras que Morosanto, La Indiana, El Cupil, el Monte de las Viñas en Benaoján, La Vizcondesa o Lagar de Peinado, todas ellas caracterizadas como villae tardorromanas, formarían parte del grupo en donde se han hallado elementos iconográficos, y en las tres últimas concretamente la serie de placas decoradas que nos ocupa (fig. 13).

La proliferación de manifestaciones cristianas en establecimientos que sin duda se pueden considerar de carácter aristocrático, no la podemos separar del hecho, cada vez más asentado en la historiografía, de que estas mismas manifestaciones, y concretamente las que se centran en la construcción de edificios de culto, no parecen poder adelantarse a momentos anteriores al siglo VI, prolongándose esta tendencia durante toda la siguiente centuria (Chavarría Arnau 2006, 2007). En este sentido, contamos con el ejemplo que nos proporciona la datación de la que en su día se determinó basílica de
Ronda. Si bien hemos señalado nuestras dudas sobre la primigenia propuesta que llevaba sus inicios hasta el siglo $\mathrm{V}$, de lo que no cabe duda es de que su continuidad se produjo cuando menos hasta bien avanzado el siglo VIII, pues en este caso, al contrario que en el anterior que se basó en una moneda de Cizyko acuñada en el siglo IV y de la que sabemos que tuvo una prolongada vigencia, la confirmación de su pervivencia vino de la mano de un triente de Égica-Witiza emitido en Gerona entre los años 698 y 702, que se encontró en una de las tumbas (Castaño Aguilar 2016).

La misma tesis apunta además a que, salvo en casos muy puntuales y aunque se encuentren en los mismos solares de las villae, estas iglesias se habrían construido probablemente tras haber perdido aquellas su carácter residencial (Chavarría Arnau 2006: 203), una propuesta especialmente sugerente para nosotros dada la intensidad con la que se constata este fenómeno religioso en nuestra zona (y para la que posiblemente tenemos un ejemplo en la villa de la Vizcondesa, caracterizada hace 
ya tiempo como un posible lugar de culto -Pérez Aguilar 1966-). Aunque no podamos generalizar y contemos todavía con poca información, el hecho de que la villa que mayor cantidad de ejemplares de la serie Bracario ha dado, Lagar de Peinado, se inserte en un ámbito en el que podría reconstruirse la secuencia de abandono de este antiguo enclave y la creación de otro nuevo dotado de elementos inéditos, como una torre, pero que creemos dentro de una misma propiedad, vendría a apoyar esa visión basada en la fundación de iglesias sobre las ruinas de la antigua residencia (Castaño Aguilar 2016. Barroso et al. 2015: 21). ¿Se trata del dominio que posibilitó a Bracario acceder a una dignidad eclesiástica, a partir de la cual funda una iglesia sobre las ruinas de la residencia heredada de sus antepasados "para que los suyos" guarden su memoria? ¿Tendría que ver esta influencia ejercida no solo ya por su capacidad como propietario, sino también por su estatus como dignatario religioso, con la generación de otras instalaciones de culto, como la basílica o las iglesias rupestres rondeñas? No deja de ser extraño al respecto, que la procedencia de las piezas conocidas con su nombre sea de aquí, lo que, con independencia de si fue él u otra persona la que promovió la erección o adaptación de ese espacio de culto, coloca a Bracario en una relación estrecha y directa con este territorio. Como es obvio no contamos con más elementos de análisis para dar respuesta a estas y otras cuestiones. En cualquier caso, la popularidad que llegó a alcanzar este personaje parece limitarse al área rondeña, habida cuenta de la inexistencia de placas con su nombre en otros lugares de la Bética, al menos por el momento, como creemos haber podido mostrar con relativa claridad.

Aun así, una cosa sí parece clara: el área de Arunda, en la que habría que incluir ya en estos momentos prácticamente toda la depresión, por algún fenómeno que de momento se nos escapa (pero en el que podría haber tenido algo que ver lo anterior), aglutinó a una aristocracia impregnada de una fuerte religiosidad. Esta religiosidad encontró en sus centros de residencia, en sus villae, los lugares idóneos para su expresión material; tal vez porque en ellos se concentraba ya una parte importante de la población, en gran medida dependiente de ellos. Unas formas de expresión que han llegado hasta nosotros de manera más explícita a través de la iconografía, como nuestros ejemplares de placas, pero también por los probables restos de algunos de estos edificios. Todo ello girando en torno a unos establecimientos de muy larga perduración, que se vieron transformados en nuevos espacios dentro de un contexto general de reordenación y redefinición de los territorios, de las personas y de las ideas.

\section{Agradecimientos}

Este trabajo no podría haberse hecho sin la contribución, puntual pero decisiva, de las siguientes personas e instituciones: Las Dras. Dña. Gabriele Mietke, del Skulpturensammlung und Museum für Byzantinische Kunst de Berlín, Dña. Julia Beltrán de Heredia, del Museu de Història de Barcelona y el Dr. D. José Miguel González Bornay, del Museo de Cáceres, por toda la información proporcionada sobre los ejemplares custodiados en sus respectivos museos. En un plano más local, la Dra. Ana Gómez, directora de Casa-Museo Bonsor de Mairena del Alcor (Sevilla), y D. José María Gutiérrez director del Museo Histórico Municipal de Villamartín, por la información correspondiente a los Bracarios conservados en las instituciones que dirigen. El prof. Dr. D. Miguel Cortés Sánchez, por la noticia del hallazgo de Parauta y a Manuel Becerra Parra, Javier Carrasco Rus y Bartolomé Nieto González por las fotografías de los ejemplares de Parauta, El Majuelo (Ronda) y el de la calle Capitán Cortés de Ronda, respectivamente. Por último, mi agradecimiento también a los profesores, Pilar Corrales Aguilar, Andrés María Adroher y Enrique García Vargas por sus oportunas aclaraciones.

\section{BIBLIOGRAFÍA}

Abascal Palazón, J. M. (1999): Fidel Fita. Su legado documental en la Real Academia de la Historia. Madrid, Real Academia de la Historia.

Aguilar y Cano, A. (1894): El libro de Puente Jenil. Puente Genil, Imp. J. Estrada Muñoz.

Alonso Sánchez, M․ A. (1982): “Crismones con $\Omega$ A en España”, en P. de Palol Salellas (dir.), II Reunió d'Arqueologia Paleocristiana Hispànica: 297-302. Monserrat (1978), Barcelona, Institut d'Arqueologia i Prehistòria.

Amores Carredano, F. y González Acuña, D. (2006): "V fase de intervención arqueológica en el Mercado de la Encarnación (Sevilla). Contextos tardoantiguos". Anuario Arqueológico de Andalucía 2003, t. III-2: 197-206.

Barroso Cabrera, R. y Morín de Pablos, J. (1994): “El nicho-placa de Salamanca del M.A.N. y otros testimonios arqueológicos del culto a San Miguel en época visigoda". Zephyrus: Revista de Prehistoria y Arqueología 46: 279-294.

Barroso, R.; Carrobles, J.; Morín, J. y Sánchez, I. M. (2015): Los Hitos (Arisgotas-Orgaz-Toledo). De 
palacio a panteón visigodo. Madrid, Ayuntamiento de Orgaz.

Brogiolo, G. P. y Chavarría Arnau, A. (2008): "El final de las villas y las transformaciones del territorio rural en Occidente (siglos V-VIII)", en C. Ferández Ochoa, V. García-Entero y F. Gil Sendino (eds.), Las villae tardorromanas en el occidente del Imperio. Arquitectura y función. IV Coloquio Internacional de Arqueología en Gijón : 194-213. Gijón (2006), Gijón, Trea.

Caballero, L.; Mateos, P. y Retuerce, M. (2003): Cerámicas tardorromanas y altomedievales en la Península Ibérica. Ruptura y continuidad. Anejo de Archivo Español de Arqueología. Madrid, CSIC.

Caballos Rufino, A. F. y Stylow, A. U. (2014): "La colección epigráfica de la Universidad de Sevilla”. Chiron 44: 87-112.

Callejo Serrano, C. (1962): "Cuatro inscripciones visigodas de Extremadura”. Ampurias 24: 244-248.

Cameron, A. (1998): El mundo mediterráneo en la Antiguedad Tardía. 396-600. Barcelona, Crítica.

Camps Cazorla, E. (1940): “Arte hispanovisigodo", en R. Menéndez Pidal (dir.), Historia de España , t. III, España Visigoda (414-711 d. C.):435-608. Madrid, Espasa Calpe

Castaño Aguilar, J. M. (dir) (2005): Carta Arqueológica de Ronda: la Ciudad. Sevilla, Consejería de Cultura, Junta de Andalucía.

Castaño Aguilar, J. M. (2007): “Antigüedad Tardía y Alta Edad Media en la Serranía de Ronda", en B. Nieto, J.M. Castaño y J. Padial, Historia de Ronda. Desde la romanización a la época musulmana: 133192, Ronda, CEDER-Serranía de Ronda.

Castaño Aguilar, J. M. (2012): “Un ejemplo de transformación del poblamiento rural durante la Antigüedad Tardía. La villa de 'Morosanto' (Ronda, Málaga)". Arqueología y Territorio Medieval 19: 9-32.

Castaño Aguilar, J. M. (2016): Antigüedad Tardía y Edad Media en la Serranía de Ronda. Tesis doctoral inédita, Universidad de Granada, http://hdl. handle.net/10481/42891.

Castelo Ruano, R. (1996): "Placas decoradas paleocristianas y visigodas de la colección Alhonoz (Écija, Sevilla)". Espacio, Tiempo y Forma, serie II, Historia Antigua 9: 467-536.

Castillo Maldonado, P. (2005): "Pro amore Dei: Donantes y constructores en la provincia Baetica tardoantigua (testimonios literarios y epigráficos)". Antiquité Tardive 13: 335-350.

Castillo Maldonado, P. (2013): "El cristianismo y las iglesias del sur peninsular en la Antigüedad Tardía: balance histórico". Habis 44: 281-303.
Castro del Río, E.; Pizarro Berengena, G. y Sánchez Ramos, I. (2006): "El conjunto arqueológico del Parque Infantil de Tráfico de Córdoba. La ocupación tardoantigua del suburbium occidental de Colonia Patricia Corduba". Anales de Arqueología Cordobesa 17: 103-118.

Cerrillo Martín de Cáceres, E. (2010): “Inscripciones de la villa de Alcántara, de Alcalá de los Ríos (sic), y ladrillos con crismón hallados en Ronda. Manuscritos copiados de otro de Francisco A. Forner en el fondo Rodríguez Moñino de la Real Academia Española". Cuadernos de Arqueología. Universidad de Navarra 18: 53-91.

Chavarría Arnau, A. (2006): “Aristocracias tardoantiguas y cristianización del territorio (siglos IV-V): ¿otro mito historiográfico?’. Rivista di Archeologia Cristiana LXXXII: 201-230.

Chavarría Arnau, A. (2007): El final de las villae en Hispania. Turnhout, Brepols

De la Rada Delgado, J. de D. (1876): "Ladrillos sepulcrales cristianos que se conservan en el Museo Arqueológico Nacional”. Museo Español de Antigüedades VII: 583-594.

De los Santos Jener, S. (1958): "Las artes en Córdoba durante la dominación de los pueblos germánicos". Boletín de la Real Academia de Córdoba de Ciencias, Bellas Letras y Nobles Artes 78: 5-50.

Di Stefano Manzella, I. (2012): "Signacula ex aere in officina: aggiornamenti e novitá di una recerca multidisciplinare". Sylloge Epigraphica Barcinonensis X: 229-246.

Esojo Aguilar, F. (2013): "Nuevas placas ornamentales con epigrafía sobre «SALVO IMERIO»". Boletín de la Asociación provincial de Museos Locales de Córdoba 14: 245-252.

Esteve Guerrero, M. (1941): “Contribución al conocimiento de Asta Regia”. Actas de la Sociedad Espanola de Antropología, Etnología y Prehistoria. Atlantis XVI: 386-401.

Fariñas del Corral, M. (2014): Antigüedades de Ronda (edición, estudio introductorio y transcripción de Rafael Valentín López Flores y Sergio Ramírez González). Ronda, Ediciones Pinsapar.

Fernández, A., Rodríguez, A, García-Dils, S. (2011): Carta Arqueológica Municpal de Alcalá del Río: la ciudad y el territorio, vol. I, textos. Recurso electrónico en internet: http://www.ilipenses.com/ documentos/carta\%20arqueologica\%20municipal/ volumen\%20I.\%20Textos/volumen\%20I.\%20Textos. pdf [28/07/2017]. 
Ferrandis Torres, J. (1940): “Artes decorativas visigodas”, en R. Menéndez Pidal (dir.), Historia de España , t. III, España Visigoda (414-711 d. C.): 609666. Madrid, Espasa Calpe.

Fita, F. (1908): “Inscripciones romanas y visigóticas de Tarifa, Ronda y Morón de la Frontera”. Boletín de la Real Academia de la Historia LIII: 344-353.

Flórez, E. (1752): España Sagrada, tomo IX : 220-223. Madrid, Oficina de Antonio Marín, pp

García García, F de A. (2010): "El crismón". Revista Digital de Iconografía Medieval, Vol. II, no 3: 21 31. https://www.ucm.es/data/cont/docs/621-201311-21-5.\%20Crism\%C3\%B3n.pdf [17/08/2017].

García Vargas, E. y Vázquez Paz, J. (2012): “El poblamiento rural en las campiñas al sur del Guadalquivir durante la Antigüedad Tardía (siglos IV-VI d. C.)", en L. Caballero, P. Mateos y T. Cordero (eds.): Visogodos y Omeyas. El territorio. Anejos de Archivo Español de Arqueología: 235 261, Mérida, CSIC.

Giménez Reyna, S. (1946): Memoria Arqueológica de la provincia de Málaga hasta 1946. Madrid, Ministerio de Educación Nacional.

Gómez de Avellaneda Sabio, C. (2011): "Placa cerámica decorada con crismón procedente de Barbesula". Almoraima 42: 521-548.

Gómez-Moreno Martínez, M. (1966): "Primicias del arte cristiano Español". Archivo Español de Arte 39: 101-139.

González Fernández, J. (2003): “San Isidoro y las fuentes epigráficas”, en González Fernández, J. (coord.), San Isidoro. Doctor de las Españas: 75-89, Sevilla, Fundación El Monte.

González Fernández, J. (1988): Inscripciones romanas $y$ visigodas de Utrera. Sevilla, Caja San Fernando.

Gozalbez Cravioto, C. (1987): "Un ladrillo de época visigoda con simbología judía hallado en Ronda (Málaga)". Miscelánea de Estudios Árabes y Hebraicos 36 (2): 89-93.

González Román, C. y Salvador Ventura, F. (1997): “La documentación epigráfica de Hispania meridional durante la Antigüedad tardía: Aproximación a su génesis y transmisión". La tradición en la Antigüedad Tardía. Antigüedad y Cristianismo XIV: 323-332.

González Virseda, M. L. y Moreno Almenara, M. (1997): "Un conjunto de placas cerámicas tardoantiguas decoradas a molde procedentes de Córdoba". Almirez 6: 123-135.

Hanel, N. y Ristow, S. (2010): "Vier frühchristliche Ziegelplatten mit Reliefverzierung aus Nordafrika und Südspanien”. Kölner Jahrbuch 43: 297-314.
Hidalgo Aguilera, R. F. (2003): "La recuperación del yacimiento romano de la Finca del Secretario". Cilniana 16: 75-80.

Hispania Epigraphica (HEp) (1998): 8.

Hübner, E. (1869): Corpus Inscriptionem Latinarum, vol. II. Berlín, Academiae Litterarum Regiae Borussicae.

Hübner, E. (1871): Inscriptiones Hispaniae Christianae. Berlín, Academiae Litterarum Regiae Borussicae.

Isla Frez, A. (2001): "Villa, villula, castellum. Problemas de terminología rural en época visigoda". Arqueología y Territorio Medieval 8: 9-19.

Laliena, C. y Ortega, J. (2005): Arqueología y poblamiento. La cuenca del río Martín en los siglos V-VIII. Zaragoza, Grupo de Investigación de Excelencia C.E.M.A. Universidad de Zaragoza.

Lara Fuillerat, J.M.; Alors Reifs, R. y Lacort Navarro, P.J. (2002): "El yacimiento romano de «Casilla de los Valerios» (Santaella, Córdoba)". Boletín de la Asociación provincial de museos locales de Córdoba 3: 221-242.

Leveau, Ph. y Loïc, B. (2008): "Les bâtiments agricoles et l'architecture des villas de la fin de l'Antiquité", en C. Fernández, V. García-Entero y F. Gil Sendino (eds.): Las villae tardoantiguas en el occidente del Imperio. Arquitectura y función. IV Coloquio Internacional de Arqueología en Gijón : 133-165. Gijón (2006), Gijón, Trea.

Loza Azuaga, M. L. (1991-1992): “Tipología y catálogo de las placas cerámicas decoradas a molde de época tardorromana y visigoda conservadas en el Museo de Málaga”. Mainake XIII-XIV: 251-265.

Maier Allende, J. (2008): Noticias de antigüedades de las actas de sesiones de la Real Academia de la Historia (1834-1874). Madrid, Academia de la Historia.

Marcos Pous, A. (1981): "Letreros de ladrillos cordobeses con la fórmula cristiana antigua «Salvo Ausentio»". Corduba Archaeologica 11: 47-68.

Martín Gómez, C. (1982): "Placas decoradas de época paleocristiana y visigoda, con inscripción, del $\mathrm{Mu}$ seo Arqueológico de Sevilla”. Museos 1: 37-43.

Medina Conde, C. (1789): Conversaciones históricas malagueñas. Málaga, Oficina del Impresor de la Dignidad Episcopal y Sta Iglesia Catedral..

Morales, A. de (1575): Las antigüedades de las ciudades de España que van nombradas en la corónica con la averiguación de sus sitios y nombres antiguos. Alcalá de Henares, Casa de Iuan Iñiguez de Lequerica.

Morena, J. A. y Sánchez, I. (2011): “Un anillo de oro con inscripción del Museo Histórico de Baena (Córdoba)". Pyrenae 42, vol. 1: 129-142. 
Moreti Sánchez, J. J. (1867): Historia de la muy noble y muy leal ciudad de Ronda. Ronda, Tipografía de J. J. Moreti.

Morín de Pablos, J. (2014): Estudio históricoarqueológico de los nichos y placas-nicho de época Visigoda en la Península Ibérica. Madrid, Audema.

Oliver y Hurtado, J. (1866): Munda pompeyana. Viaje arqueológico. Madrid, M. Rivadeneira.

Ordóñez Agulla, S. y Ruiz Cecilia, J. I. (2015a): "CIL II ${ }^{2} / 5,1113$ y la ubicación de un edificio cultual cristiano en las inmediaciones de la Osuna tardoantigua". Cuadernos de Prehistoria y Arqueología de la Universidad de Granada 25: 349-372.

Ordóñez Agulla, S. y Ruiz Cecilia, J. I. (2015b): “544. Placa decorada cristiana". Ficheiro Epigráfico (suplemento de Conimbriga): 129.

Ordóñez Agulla, S. y Ruiz Cecilia, J. I. (2016): “CIL II²/7, 87a: las placas decoradas del figulus Restitutus". Sylloge Epigraphica Barcinonensis XIV: 35-45.

Palol, P de (1956): "Esencia del arte hispánico de época visigoda: romanismo y germanismo", en Settimane di Studio del Centro Italiano di Studi sull'Arte Medioevo. III. I Goti in Occidente. Problemi : 65-126. Spoleto (1955), Spoleto, CISAM.

Pérez Aguilar, A. (1966): “¿Una basílica paleo-cristiana en Ronda? (Málaga)”, en IX Congreso Nacional de Arqueología : 397-404. Valladolid (1965), Zaragoza, Universidad de Zaragoza.

Puertas Tricas, R. (1986-1987): "Los hallazgos arqueológicos de Torreblanca del Sol (Fuengirola)". Mainake VIII-IX: 145-200.

Recio, A. y Fernández-Chicarro, C. (1959): "La colección de antigüedades arqueológicas del padre Fr. Alejandro Recio: objetos procedentes de Martos (Jaén) y su término". Boletín del Instituto de Estudios Giennenses 20, año II: 121-159.

Ripoll, G. y Arce, J. (2001): “Transformación y final de las villae en occidente (siglos IV-VIII): problemas y perspectivas". Arqueología y Territorio Medieval 8: 21-54.

Rivera Valenzuela, J. M. (1873): Diálogos de memorias eruditas para la historia de la nobilísima ciudad de Ronda núm. I. Ronda, Imprenta y Librería de la Sra. Viuda de Gutierrez (primera ed. Córdoba, 1766).

Rodríguez de Berlanga, M. (1903): Catálogo del Museo Loringiano. Málaga, Tip. de Arturo Gilabert.

Román Punzón, J. M. y Ruiz Cecilia, J. I. (2007): "La colección de placas tardoantiguas del Museo
Arqueológico de Osuna (Sevilla)". Antiquitas 1819: $127-139$

Román Punzón, J. M. y Ruiz Cecilia, J. I. (2009): "Reflexiones sobre Osuna tardoantigua". Cuadernos de amigos de los museos de Osuna 11: 14-16.

Romero de Torres, E. (1911): "Montilla romana y visigoda. Nuevos descubrimientos". Boletín de la Real Academia de la Historia LVIII: 75-81.

Romero de Torres, E. (1919): "Nuevos descubrimientos arqueológicos en la provincia de Córdoba". Boletín de la Real Academia de la Historia LXXXIV: 135-140.

Romero, M.; Cisneros, M.; Espinar, A.; Fernández, L. y Melero, F. (2013-2014): "Villas romanas en la depresión de Antequera: novedades desde la arqueología preventiva". Romula 12-13: 221-282.

Rubio Lapaz, J. (1994): “La arqueología clásica de Andalucía en las investigaciones humanistas del Siglo de Oro", en Recuerdos de Ronda y su Historia (II):19211. Sevilla, Colectivo Cultural Giner de los Ríos.

Ruiz Cecilia, J. I. y Román Punzón, J. M. (2015): “Las placas cerámicas decoradas tardoantiguas con iconografía cristiana en el sur de la península ibérica". Anuario de Historia de la Iglesia Andaluza III: 11-53.

Ruiz González, H. (2014): "Las placas cerámicas decoradas de la Antigüedad Tardía: un análisis morfológico e iconográfico de los materiales encontrados en la actual Andalucía”.@rqueología y Territorio 11: 113-122.

Ruiz Prieto, E. (2012): "Las placas cerámicas decoradas del Museo Arqueológico de Sevilla: morfología, iconografía y contextualización". Revista de Clases historia. Publicación digital de Historia y Ciencias Sociales, art. 286 , 58 págs. Publicación on line: http://www.claseshistoria.com/revista/2012/articulos/ruiz-placas-museo.pdf (15 marzo 2012).

Ruiz Torres, S. (2006): “Los ladrillos con simbología paleocristiana de Ronda”. Cuadernos de Arqueología de Ronda 2: 101-115.

Sáez Fernández, P.; Ordóñez Agulla, S. y García-Dils de la Vega, S. (2003): "Inscripciones romanas inéditas en la provincia de Sevilla". Habis 34: 229-257.

Salas Álvarez, J. (2010): La arqueología en Andalucía durante la Ilustración: (1736-1818). Anejos de la Revista Mainake. Málaga, Centro de Ediciones de la Diputación de Málaga.

Salvador Oyonate, J. A. (2011): La Bastitania romana y visigoda: historia de un territorio. Granada. Publicación on line: http://hdl.handle.net/10481/19215.

Salvador Ventura, F. (1990): "Ciudad y campo en Hispania meridional durante los siglos VI y VIII". Florentia Iliberritana 1: 409-422. 
Sánchez Ramos, I. M. et al. (2015): “Topografía eclesiástica de la Bética en la Antigüedad Tardía a través del corpus epigráfico". Romula 14: 221-265.

Sánchez Velasco, J.; Moreno Rosa, A. y Gómez Muñoz, G. (2009): “Aproximación al estudio de la ciudad de Cabra y su obispado al final de la Antigüedad". Antiquitas 21: 135-180.

Santiago Fernández, J de. (2009): “El hábito epigráfico en la Hispania visigoda”, en J. C. Galende Díaz y J. de Santiago Fernández (dirs.), VIII Jornadas científicas de documentación de la Hispania altomedieval (siglos VI-X): 291-344. Madrid, Universidad Complutente .

Sastre de Diego, I. (2012): “Aristocracia, cristianismo y epigrafía laica en la Hispania tardoantigua”. $\mathrm{Ve}$ leia 29, 17-27.

Serrano Ramos, E. (1973): “Materiales de Manguarra y San José (Cártama)”. Jábega 1, 67-70.

Schlunk, H. (1944): "El arte decorativo visigodo". Boletín Bibliográfico, año XII, n ${ }^{\circ}$ 1-2 enero-junio: 14-34.

Schlunk, H. y Hauschild, T. (1978): Hispania Antiqua. Die Denkmäler der frühchristlichen und westgotischen Zeit, Maguncia, Philipp von Zabern Verlag.

Schneider, L. (2005): "Dynamiques spatiales et transformations de l'habitat en Languedoc méditerranéen durant le Haut Moyen Âge (VI-IX s.)", en G.P. Brogiolo, A. Chavarría y M. Valenti (eds), Dopo la fine delle ville: le campagne dal VI al IX secolo: 287-312. Mantua, Società Archeologica Padana,

Serrano Ramos, E. y Atencia Páez, R. (1981): Inscripciones latinas del Museo de Málaga. Madrid, Ministerio de Cultura.

Solano Gálvez de San Pelayo y Villalpando, M. C. (Marqués de Monsalud) (1897): "Nuevas inscripciones romanas y visigóticas". Boletín de la Real Academia de la Historia XXXI: 391-404.

Sotomayor Muro, M. (2002): “Sedes episcopales hispanorromanas, visigodas y mozárabes en Andalucía”, en C. González Román y A. Padilla Arroba, Estudios sobre ciudades de la Bética: 463-496. Granada, Universidad de Granada.

Sotomayor Muro, M. (2002): "Penetración de la iglesia en los medios rurales de la España tardorromana y visigoda", en Discípulos de la Historia: 241-271, Granada, Universidad de Granada.
Stylow, A. U. (1997): “¿SALVO IMPERIO? A propósito de las placas ornamentales con la inscripción IHC $197=432 "$. Singilis 2: 19-31.

Stylow, A. U. (2005): "El culto a San Miguel en la Hispania visigoda: una revisión crítica", en L. A. García Moreno y S. Rascón Marqués (eds.), Actas del IV y V encuentro internacional 'Hispania en la Antigüedad Tardía'. Guerra y rebelión en la Antigüedad Tardía. El siglo VII en España y su contexto mediterráneo: 213-223. Alcalá de Henares, Ayuntamiento de Alcalá de Henares.

Tabales Rodríguez, M. Á. (2015): Excavaciones arqueológicas en el Patio de Banderas. Alcázar de Sevilla. Memoria de investigación, 2009-2014. Sevilla, Ayuntamiento de Sevilla, Patronato del Real Alcázar de Sevilla.

Téllez Sánchez, V. (2001): Al Sur de Ronda. Ronda, La Serranía.

Vargas Cantos, S. et al. (2007a): "Los conjuntos cerámicos tardoantiguos de un edificio cristiano en el sector occidental de Corduba", en M. Bonifay y J. C. Tréglia, $L R C W$ 2. Late Roman Coarse Wares, Cooking Wares and Amphorae in the Mediterranean: Archaeology and archaeometry, Vol. I. BAR International Series 1162: 177-188, Oxford, Archaeopress.

Vargas Cantos, S. et al. (2007b): "Los contextos cerámicos tardoantiguos de un solar anexo a la Puerta del Puente de Córdoba", en M. Bonifay y J. C. Tréglia, LRCW 2. Late Roman Coarse Wares, Cooking Wares and Amphorae in the Mediterranean: Archaeology and archaeometry, Vol. I. BAR International Series 1162: 165-175. Oxford, Archaeopress.

Vera Reina, M. (1999): "La iglesia visigoda de Morón de la Frontera (Sevilla)". Spal 8: 217-239. DOI: http://dx.doi.org/10.12795/spal.1999.i8.12

Vera Reina, M. (2000): Mawrur. Morón. Análisis arqueológico de una ciudad medieval. Morón de la Frontera, Altos del sur de Sevilla.

Vives, J. (1969): Inscripciones cristianas de la España romana y visigoda. Barcelona, CSIC.

Ward-Perkins, B. (2007): La caida de Roma y el fin de la civilizacion. Madrid, Espasa.

Wickham, Ch. (2008): Una historia nueva de la Alta Edad Media. Europa y el mundo mediterráneo, 400-800. Barcelona, Crítica. 